\title{
Dipeptidyl peptidase-4 inhibitors and the risk of heart failure: a systematic review and meta-analysis
}

\author{
Subodh Verma MD PhD, Ronald M. Goldenberg MD, Deepak L. Bhatt MD MPH, \\ Michael E. Farkouh MD MSc, Adrian Quan MPhil, Hwee Teoh PhD, Kim A. Connelly MBBS PhD, \\ Lawrence A. Leiter MD, Jan O. Friedrich MD DPhil
}

\section{Abstract}

Background: Given recent discrepant results from randomized controlled trials (RCTs), we examined the totality of RCT evidence assessing the association between dipeptidyl peptidase-4 (DPP-4) inhibitors and heart failure.

Methods: MEDLINE, Embase and ClinicalTrials.gov were searched without language restrictions to August 2016 for RCTs comparing DPP-4 inhibitors to placebo or no therapy for a period of 24 weeks or more. We included all heart failure outcomes when listed either as a serious adverse event or adverse event. Pooled analyses used random-effects.

Results: We identified 100 RCTs ( $n=79$ 867) - 3 large cardiovascular-safety RCTs (SAVOR-TIMI 53[saxagliptin]/ $n=16$ 492, EXAMINE[alogliptin] $/ n=5380$, and TECOS[sitagliptin] $/ n=14735$ ), and 97 smaller RCTs with a primary outcome that was usually change in glycated hemoglobin. Virtually all RCTs were high-quality, multicentre, placebo-controlled trials. A total of 96\% (1192/1244) of heart failure events were prespecified, blindly adjudicated and required hospital admission. Pooled results suggested a $13 \%$ increase in heart failure (relative risk [RR] 1.13, 95\% confidence interval $[\mathrm{Cl}] 1.01-1.26, l^{2}=0 \%$; $32 \mathrm{RCTs}, n=54640,1244$ events). When including only the 3 large RCTs, the increase was similar, but not significant (RR 1.14, 95\% Cl 0.97-1.32; 3 RCTs, $n=36543$, 1169 adjudicated events; number needed to harm 246$)$ owing to heterogeneity $\left(I^{2}=42 \%\right)$, which lead to wider Cls, because SAVORTIMI 53 showed increased heart failure (RR 1.26, 95\% CI 1.06-1.49) and TECOS showed no effect (RR 1.00, 95\% CI 0.83-1.19).

Interpretation: Despite pooled data from 79867 patients, whether DPP-4 inhibitors increase heart failure overall or exhibit withinclass differences remains unresolved. Our results highlight the importance of ongoing trials that are comparing DPP-4 inhibitors to placebo, although no large cardiovascular-safety RCTs are comparing different DPP-4 inhibitors to each other; consequently, these will address the overall but not class-difference question.

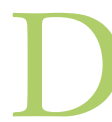
ipeptidyl peptidase-4 (DPP-4) inhibitors are integral in the management of diabetes because of their effective glucose lowering with low risk for hypoglycemia or weight gain. ${ }^{1}$ Because heart failure remains a common complication of diabetes and is associated with poor longterm prognosis, ${ }^{2,3}$ understanding the potential effects of antihyperglycemic agents on risk for heart failure is of critical and immediate importance. The first large DPP-4 inhibitor versus placebo randomized controlled trial (RCT) Saxagliptin Assessment of Vascular Outcomes Recorded in Patients with Diabetes Mellitus - Thrombolysis in Myocardial Infarction 53 (SAVOR-TIMI 53) ( $n=16492$ patients with a history of, or at risk for, cardiovascular events) unexpectedly found a significantly higher rate of heart failure requiring admission to hospital. ${ }^{4,5}$ The second was the Examination of Cardiovascular Outcomes with Alogliptin versus Standard of Care (EXAMINE) ( $n=5380$ patients post-acute coronary syndrome), which found a numerical but nonsignificantly higher rate of heart failure requiring hospital admission. ${ }^{6,7}$ In contrast, Trial to Evaluate Cardiovascular Outcomes after Treatment with
Sitagliptin (TECOS) $(n=14735$ patients with cardiovascular disease and longer follow-up [median $3.0 \mathrm{yr}$ v. 1.5 and $2.1 \mathrm{yr}$ for EXAMINE and SAVOR-TIMI 53]) found almost identical rates of hospital admission for heart failure in the sitagliptin and placebo groups. ${ }^{8}$

The potential safety issue that arose from SAVOR-TIMI 53 and EXAMINE led to the Food and Drug Administration's (FDA) recommendation ${ }^{9}$ to consider discontinuing saxagliptin and alogliptin for patients if heart failure develops. Given the apparent discrepant results from TECOS, ${ }^{3,10,11}$ we felt it was important to inform clinicians who are concerned about the potential increased heart failure signal by providing them with

Competing interests: See end of article.

This article has been peer reviewed.

Correspondence to: Jan Friedrich, j.friedrich@utoronto.ca

CMAJ Open 2017. DOI:10.9778/cmajo.20160058 
the totality of the available RCT evidence in the field. In addition, the publication of the Empagliflozin, Cardiovascular Outcomes, and Mortality in type 2 Diabetes [EMPA-REG OUTCOMES] trial, ${ }^{12}$ which shows that hopspital admission for heart failure was significantly reduced with the use of an oral antihyperglycemic agent of a different class, empagliflozin, a sodium-glucose cotransporter 2 (SGLT2) inhibitor, has increased the importance of quantifying the risk of increased heart failure for DPP-4 inhibitors. The 2 specific questions addressed by this systematic review and meta-analysis are whether DPP-4 inhibitors, as a class, compared with placebo or no therapy, increases heart failure in patients with type 2 diabetes, and whether there are significant within-class differences.

\section{Methods}

\section{Data sources and study selection}

We systematically searched MEDLINE and Embase (inception to August 2016) and ClinicalTrials.gov in duplicate for RCTs that compared treatment with any DPP-4 inhibitor with either placebo or no therapy (active comparator RCTs were excluded) and that enrolled adult patients with type 2 diabetes for at least 24 weeks. For multiple treatment group RCTs, we included only randomized groups in which treatments differed by DPP-4 inhibitor treatment. Groups with different DPP-4 inhibitor doses were combined within the same trial. Trials in which placebo groups were subsequently switched to open-label active therapy were only included if this switch occurred after 24 weeks of therapy.

\section{Data extraction and risk of bias assessment}

For each RCT, baseline patient characteristics, intervention, outcome definitions and events were collected in duplicate (discrepancies resolved by consensus). Risk of bias (patient, caregiver and outcome assessor blinding; allocation concealment; intention-to-treat analysis; early stopping for benefit; ${ }^{13}$ loss to follow-up) were also assessed in duplicate. ${ }^{14}$

\section{Data analysis}

In the primary analysis, we included all heart failure outcomes when listed either as a serious adverse event or adverse event. In 2 separate secondary analyses, we included only RCTs in which (1) cardiovascular outcomes were the primary outcome, and (2) hospital admission for heart failure was an adjudicated primary or secondary outcome. Additional data analysis details, including sensitivity analysis, are provided in the online appendix (Appendix 1, available at www.cmajopen.ca/content/5/1/E152/suppl/ DC1). We did not register or publish a review protocol.

\section{Results}

\section{Search results}

We identified 121 RCTs in which treatment between randomized groups differed only by DPP-4 inhibitor treatment. Of these, 11 RCTs listed only on ClinicalTrials.gov provided no results (NCT00683735, NCT01356381, NCT01582230, NCT01697592, NCT01704261, NCT01792518,
NCT01890122, NCT01990469, NCT02015299, NCT02099110, NCT02104804) and 10 RCT publications did not provide heart failure data, ${ }^{15-24}$ leaving 100 RCTs that reported the number of patients with heart failure (Appendix 1, Figure 1), which enrolled 79867 patients into groups that differed only in DPP-4 inhibitor therapy. ${ }^{4-8,25-47,49-88,90-95,97-139}$

\section{RCT patient characteristics}

Only 3 RCTs, SAVOR-TIMI 53, EXAMINE and TECOS, had cardiovascular outcomes as the primary outcome; they enrolled 46\% (36 543/79 867) of all patients in the included RCTs (Table 1, Table 2). Enrolled patients in these 3 RCTs had a mean age of 61-66 years, two-thirds of participants were men and about $70 \%$ were white. Median body mass index (BMI) was about $30 \mathrm{~kg} / \mathrm{m}^{2}$. The patients had type 2 diabetes for median durations that ranged from 7-10 years, with a mean baseline glycated hemoglobin (A1C) of 8.0\% (SAVOR-TIMI 53 , EXAMINE) or $7.2 \%$ (TECOS), and a mean of $23 \%-41 \%$ participants taking insulin in addition to oral antihyperglycemic agents. Many patients had other cardiovascular risk factors, including hypertension and dyslipidemia, and most had a previous myocardial infarction or revascularization, although only a few had a previous stroke (Table 2). Most patients were receiving acetylsalicylic acid (ASA) with or without another antiplatelet therapy, as well as a statin, angiotensin-converting enzyme inhibitors or angiotensin receptor antagonists, and $\beta$-blockers or other antihypertensive medications. The proportion of patients with pre-existing heart failure ranged from 13\%-28\% among the included larger RCTs.

The primary outcome for most of the smaller RCTs $(n=$ 89/97) was glycemic control. One small trial, presented only in abstract form, ${ }^{113}$ enrolled patients with New York Heart Association class I-III heart failure and measured change in left ventricular ejection fraction as its primary outcome. Enrolled patients in these smaller trials had variable characteristics (Table 1). Mean age was typically in the mid-50s, with more than $50 \%$ men, and more than $50 \%$ of white race, and median BMI was about $30 \mathrm{~kg} / \mathrm{m}^{2}$. The mean duration of type 2 diabetes ranged from 0 to 17 years, with most mean baseline A1C levels between $8.0 \%$ and $8.5 \%$. No patients were using insulin therapy in most of the smaller RCTs. Few data were provided on the prevalence of other cardiovascular risk factors or cardiovascular medication use in the smaller RCTs.

\section{Risk of bias assessment}

Included RCTs generally had low risk of bias. The 3 large RCTs and all trials with events were blinded using placebos with concealed allocation, intention-to-treat analysis, no stopping early for benefit and had low numbers (typically < $1 \%-5 \%)$ of randomized patients with missing heart failure outcome data (Table 3). Only 7 of the smaller trials, each with 0 events, were not blinded or had unclear allocation concealment, ${ }^{34,80,101,106,108,129,133}$, and only 4 had more than $5 \%$ of randomized patients lost to follow-up. ${ }^{34,88,125,129}$ The 3 larger trials, in addition to the small trial that enrolled patients with class I-III heart failure, ${ }^{113}$ defined heart failure that required admission to hospital as a prespecified secondary outcome 
that was adjudicated by outcome assessors blinded to treatment allocation. The 3 larger trials used virtually identical definitions of heart failure (Table 2). Virtually all RCTs were funded by pharmaceutical companies.

\section{Quantitative data synthesis}

All heart failure outcomes were listed as serious adverse events. Pooling heart failure data from the 3 larger RCTs and the 29 smaller RCTs with at least 1 patient with heart failure suggested a $13 \%$ increased risk of heart failure with DPP-4 inhibitors, which achieved significance (pooled relative risk [RR] $1.13,95 \%$ confidence interval $[\mathrm{CI}] 1.01-1.26, p=0.03 ; 32$ RCTs, 54640 patients, 1244 events) with no significant heterogeneity $\left(I^{2}=0 \%\right)$ (Figure 2). A total of $94 \%(1169 / 1244)$ of the events came from the 3 larger RCTs, and 23 of the remaining 75 (31\%) events reported in the 29 smaller RCTs occurred in the trial that enrolled patients with class I-III heart failure. Thus, 1192/1244 (96\%) of heart failure outcomes occurred in RCTs that prespecified that these required admission to hospital and were subject to blinded adjudication. Including the results from the 68 smaller RCTs $(n=25227)$ with no patients with heart failure and thus an RR of 1.00 (or no effect), as the preplanned sensitivity analysis, did not change the pooled result (pooled RR 1.12, 95\% CI 1.01-1.25, $p=0.03, I^{2}=0 \% ; 100$ RCTs, 79867 patients, 1244 events).

Pooling data from only the 3 large RCTs with cardiovascular primary outcomes and blinded outcome adjudication, as the preplanned secondary analysis, resulted in a similar effect size; however, this did not achieve significance (pooled RR 1.14, 95\% CI 0.97-1.32, $p=0.10 ; 3$ RCTs, 36543 patients, 1169 [adjudicated] events), partly because of heterogeneity $\left(I^{2}=\right.$ $42 \%$ ) that resulted in wider CIs (the pooled result would be significant if fixed-effects meta-analysis, which ignores heterogeneity, were used: pooled RR 1.14, 95\% CI 1.01-1.27, $p=$ $0.03)$. Adding the results of the smaller trial that enrolled patients with class I-III New York Heart Association heart failure and defined heart failure that required hospital admission as a prespecified secondary outcome that was adjudicated by outcome assessors blinded to treatment allocation, gives a pooled result that just achieves statistical significance (pooled RR 1.139, 95\% CI 1.002-1.293, $p=0.046$; 4 RCTs, 36796 patients, 1192 [adjudicated] events). There was no difference in the pooled result of the 3 larger RCTs with cardiovascular primary outcomes and the pooled result of the smaller RCTs (interaction $p=0.54$ ) (Figure 2).

Differences between pooled RR for individual DPP-4 inhibitors (Figure 3) did not achieve significance. The most extreme difference was between saxagliptin, dominated by the results of SAVOR-TIMI 53, which suggested a significantly increased risk of heart failure requiring hospital admission (pooled RR 1.22, 95\% CI 1.03-1.44, $p=0.02, I^{2}=0 \% ; 9$ RCTs, 20880 patients, 536 events), and sitagliptin, dominated by the results of TECOS, which suggested no difference in risk (pooled RR 1.01, 95\% CI 0.85-1.21, $p=0.89, I^{2}=$ 0\%; 10 RCTs, 21218 patients, 468 events). However, even this difference in pooled RR between saxagliptin and sitagliptin did not achieve significance (interaction $p=0.13$ [inter- action $p=0.07$ comparing RR for only SAVOR-TIMI $53 \mathrm{v}$. RR for only TECOS]).

In post hoc analysis, only SAVOR TIMI-53 and EXAMINE provided data for patients with and without a history of heart failure. Rates of heart failure that required hospital admission were considerably higher among patients with (359/3638 [9.9\%]) than without (353/3638 [1.9\%]) a history of heart failure, but the increase was concentrated in patients without (RR 1.42, 95\% CI 1.15-1.74) rather than with (RR $1.08,95 \%$ CI $0.89-1.31$ ) a history of heart failure (interaction $p=0.06$ ) (Figure 4). However, cautious interpretation is needed given the limited data.

\section{Interpretation}

Pooled data from all RCTs $(n=79867)$ in which intervention and control patients differed only by DPP-4 inhibitor therapy suggest that DPP-4 inhibitors increase the risk of heart failure requiring hospitalization by $13 \%(1 \%-26 \%, p=0.03)$. This increase is significant if data from both large and small high-quality RCTs are included (primary analysis), or if data from the 3 large RCTs $\mathrm{s}^{4-8}$ and 1 smaller RCT ${ }^{113}$ that defined heart failure requiring hospital admission as a prespecified secondary outcome adjudicated by outcome assessors blinded to treatment allocation are included (secondary analysis). If, however, data from only the 3 large RCTs with primary cardiovascular outcomes are included, ${ }^{4-8}$ the magnitude remains numerically similar, but is no longer significant, largely owing to heterogeneity between the risk of heart failure with saxagliptin and sitagliptin. Unfortunately, the current data do not have sufficient statistical power to definitively answer either the question of whether DPP-4 inhibitors as a class increase heart failure given pooled treatment effect $p$ values ranging from 0.03 to 0.10 , depending on whether or not the smaller RCT data are included, or whether DPP-4 inhibitors show significant withinclass differences (in which case pooling would not be appropriate) given interaction $p$ values ranging from $0.07-0.13$ that compare results between the 2 medications with the most extreme safety (sitagliptin) or harm (saxagliptin) results. Results from the 2 ongoing DPP-4 inhibitor versus placebo cardiovascular safety RCTs will be important because they could have an impact on the pooled risk estimates for heart failure among the cardiovascular safety RCTs (see Appendix 1), which emphasizes the importance of ongoing trials to resolve the question of whether DPP-4 inhibitors as a class increase heart failure. Because there are only single large cardiovascular safety RCTs for each specific DPP-4 inhibitor and few head-to-head comparisons (our search identified 11 small short-term RCTs $\mathrm{s}^{23,109,140-148}$ directly comparing agents but none reported any heart failure events), the ongoing cardiovascular safety trials will be less helpful in identifying differential effects among DPP-4 inhibitors.

In comparison to previous systematic reviews, ${ }^{149-154}$ ours focuses on RCTs in which randomized groups differed by DPP-4 inhibitor treatment to avoid the confounding effect of other medications, some of which are known to independently increase or decrease the risk of heart failure, ${ }^{12,155}$ and is unique in its comparison of differences in heart failure outcomes between different agents (Table 4). 


\section{Limitations}

Our meta-analysis has limitations. It included relatively small trials with variable inclusion criteria, short follow-up times (although we specified minimum of 24 weeks, which is longer than the 12 weeks follow-up used in some other meta-analyses $^{150,151,153}$ ) and non-adjudicated outcomes. However, 96\% of the heart failure outcomes were blindly adjudicated, and pooled results are dominated by the large cardiovascular safety trials with adjudicated outcomes: point estimates are similar regardless of whether the data from the smaller trials are included (1.14 v. 1.13), although inclusion of the additional data from the smaller RCTs narrows the confidence intervals, resulting in significance being achieved. This is in contrast to a highly cited rosiglitazone meta-analysis, ${ }^{156}$ where smaller RCTs with non-adjudicated outcomes drove overall results and the effect on both myocardial infarction and cardiovascular death changed depending on how the analysis was conducted. ${ }^{157}$ Nevertheless, the absolute increase in risk during follow-up, even limiting the analysis only to the 3 cardiovascular safety RCTs, is small at about 0.4\% (623/18 313 to $546 / 18$ 230) (Figure 2), corresponding to a number needed to harm of (1/0.004) 246 (median follow-up 2.4 year). Studies involving patients with previous heart failure and longer follow-up data may uncover higher risks, and are needed to explore longer-term safety of these lifelong therapies. Although we limited our analysis to placebo-controlled trials, in trials targeting $\mathrm{A} 1 \mathrm{C}$, patients who received placebo would likely have received more non-DPP-4 inhibitor medications.

\section{Conclusion}

In summary, our updated systematic review includes more RCTs than others and is the only post-TECOS meta-analysis to show statistically higher, albeit small, overall heart failure risk, but only if data from all placebo-controlled RCTs are included. However, despite pooled data from 79867 patients, whether DPP-4 inhibitors increase heart failure overall, or exhibit within-class differences (which would make pooling between agents inappropriate), remains unresolved, which highlights the importance of ongoing trials that will address the overall but not class difference question. Nevertheless, given the current data, it seems prudent to follow the FDA's Drug Safety Communication ${ }^{9}$ and be cautious about prescribing saxagliptin and alogliptin in patients with established heart failure or at high risk of developing heart failure (previous heart failure, low estimated glomerular filtration rate or elevated N-terminal pro b-type natriuretic peptide), and consider discontinuing these medications in any patient who develops heart failure.

\section{References}

1. Connelly KA, Yan AT, Leiter LA, et al. Cardiovascular implications of hypoglycemia in diabetes. Circulation 2015;132:2345-50.

2. Gilbert RE, Krum H. Heart failure in diabetes: effects of anti-hyperglycaemic drug therapy. Lancet 2015;385:2107-17.

3. McMurray JJ, Gerstein HC, Holman RR, et al. Heart failure: a cardiovascular outcome in diabetes that can no longer be ignored. Lancet Diabetes Endocrinol 2014;2:843-51

4. Scirica BM, Bhatt DL, Braunwald E, et al.; SAVOR-TIMI 53 Steering Committee and Investigators. Saxagliptin and cardiovascular outcomes in patients with type 2 diabetes mellitus. N Engl f Med 2013;369:1317-26.

5. Scirica BM, Braunwald E, Raz I, et al.; SAVOR-TIMI 53 Steering Committee and Investigators. Heart failure, saxagliptin, and diabetes mellitus: observations from the SAVOR-TIMI 53 randomized trial. Circulation 2014;130:1579-88.

6. White WB, Cannon CP, Heller SR, et al.; EXAMINE Investigators. Alogliptin after acute coronary syndrome in patients with type 2 diabetes. N Engl 7 Med 2013;369:1327-35

7. Zannad F, Cannon CP, Cushman WC, et al.; EXAMINE Investigators. Heart failure and mortality outcomes in patients with type 2 diabetes taking alogliptin versus placebo in EXAMINE: a multicentre, randomised, doubleblind trial. Lancet 2015;385:2067-76.

8. Green JB, Bethel MA, Armstrong PW, et al.; TECOS Study Group. Effect of sitagliptin on cardiovascular outcomes in type 2 diabetes [published erratum in N Engl 7 Med 2015;373:586]. N Engl 7 Med 2015;373:232-42.

9. Diabetes medications containing saxagliptin and alogliptin: drug safety communication Risk of heart failure. Silver Spring (MD,): U.S. Food and Drug Administration; 2016.

10. Cavender MA, Steg PG, Smith SC Jr, et al.; REACH Registry Investigators. Impact of diabetes mellitus on hospitalization for heart failure, cardiovascular events, and death: outcomes at 4 years from the Reduction of Atherothrombosis for Continued Health (REACH) registry. Circulation 2015;132:923-31.

11. Udell JA, Cavender MA, Bhatt DL, et al. Glucose-lowering drugs or strategies and cardiovascular outcomes in patients with or at risk for type 2 diabetes: a metaanalysis of randomised controlled trials. Lancet Diabetes Endocrinol 2015;3:356-66.

12. Zinman B, Wanner C, Lachin JM, et al.; EMPA-REG OUTCOME Investigators. Empagliflozin, cardiovascular outcomes, and mortality in type 2 diabetes. $N$ Engl 7 Med 2015;373:2117-28.

13. Montori VM, Devereaux PJ, Adhikari NK, et al. Randomized trials stopped early for benefit: a systematic review. FAMA 2005;294:2203-9.

14. Higgins JP, Altman DG, Gøtzsche PC, et al.; Cochrane Bias Methods Group. Cochrane Statistical Methods Group. The Cochrane Collaboration's tool for assessing risk of bias in randomised trials. BM7 2011;343:d5928.

15. Dejager S, Razac S, Foley JE, et al. Vildagliptin in drug-naive patients with type 2 diabetes: a 24-week, double-blind, randomized, placebo-controlled, multiple-dose study. Horm Metab Res 2007;39:218-23.

16. Kothny W, Foley J, Kozlovski P, et al. Improved glycaemic control with vildagliptin added to insulin, with or without metformin, in patients with type 2 diabetes mellitus. Diabetes Obes Metab 2013;15:252-7.

17. Kothny W, Shao Q, Groop PH, et al. One-year safety, tolerability and efficacy of vildagliptin in patients with type 2 diabetes and moderate or severe renal impairment. Diabetes Obes Metab 2012;14:1032-9.

18. Lukashevich V, Schweizer A, Shao Q, et al. Safety and efficacy of vildagliptin versus placebo in patients with type 2 diabetes and moderate or severe renal impairment: a prospective 24-week randomized placebo-controlled trial. Diabetes Obes Metab 2011;13:947-54.

19. Pi-Sunyer FX, Schweizer A, Mills D, et al. Efficacy and tolerability of vildagliptin monotherapy in drug-naive patients with type 2 diabetes. Diabetes Res Clin Pract 2007;76:132-8.

20. Su Y, Su YL, Lv LF, et al. A randomized controlled clinical trial of vildagliptin plus metformin combination therapy in patients with type II diabetes mellitus. Exp Ther Med 2014;7:799-803.

21. Bergenstal RM, Forti A, Chiasson JL, et al. Efficacy and safety of taspoglutide versus sitagliptin for type 2 diabetes mellitus (T-emerge 4 trial). Diabetes Ther 2012;3:13.

22. Sato S, Saisho Y, Kou K, et al. Efficacy and safety of sitagliptin added to insulin in Japanese patients with type 2 diabetes: the EDIT randomized trial. PLoS One 2015;10:e121988.

23. Inagaki N, Onouchi H, Maezawa $\mathrm{H}$, et al. Once-weekly trelagliptin versus daily alogliptin in Japanese patients with type 2 diabetes: a randomised, double-blind, phase 3, non-inferiority study. Lancet Diabetes Endocrinol 2015;3:191-7.

24. Linjawi S, Sothiratnam R, Sari R, et al. The study of once- and twice-daily biphasic insulin aspart 30 (BIAsp 30) with sitagliptin, and twice-daily BIAsp 30 without sitagliptin, in patients with type 2 diabetes uncontrolled on sitagliptin and metformin-The Sit2Mix trial. Prim Care Diabetes 2015;9:370-6.

25. Green JB, Bethel MA, Paul SK, et al. Rationale, design, and organization of a randomized, controlled Trial Evaluating Cardiovascular Outcomes with Sitagliptin (TECOS) in patients with type 2 diabetes and established cardiovascular disease. Am Heart 7 2013;166:983-9.e7.

26. Nauck MA, Ellis GC, Fleck PR, et al.; Alogliptin Study 008 Group. Efficacy and safety of adding the dipeptidyl peptidase-4 inhibitor alogliptin to metformin therapy in patients with type 2 diabetes inadequately controlled with metformin monotherapy: a multicentre, randomised, double-blind, placebocontrolled study. Int 7 Clin Pract 2009;63:46-55.

27. DeFronzo RA, Fleck PR, Wilson CA, et al.; Alogliptin Study 010 Group. Efficacy and safety of the dipeptidyl peptidase-4 inhibitor alogliptin in patients with type 2 diabetes and inadequate glycemic control: a randomized, double-blind, placebo-controlled study. Diabetes Care 2008;31:2315-7.

28. Pratley RE, Kipnes MS, Fleck PR, et al.; Alogliptin Study 010 Group. Efficacy and safety of the dipeptidyl peptidase-4 inhibitor alogliptin in patients with type 2 diabetes inadequately controlled by glyburide monotherapy. Diabetes Obes Metab 2009;11:167-76.

29. Pratley RE, Reusch JE, Fleck PR, et al.; Alogliptin Study 009 Group. Efficacy and safety of the dipeptidyl peptidase-4 inhibitor alogliptin added to pioglitazone in patients with type 2 diabetes: a randomized, double-blind, placebocontrolled study. Curr Med Res Opin 2009;25:2361-71. 
30. Rosenstock J, Rendell MS, Gross JL, et al. Alogliptin added to insulin therapy in patients with type 2 diabetes reduces $\mathrm{HbA}(1 \mathrm{C})$ without causing weight gain or increased hypoglycaemia. Diabetes Obes Metab 2009;11:1145-52.

31. Rosenstock J, Inzucchi SE, Seufert J, et al. Initial combination therapy with alogliptin and pioglitazone in drug-naive patients with type 2 diabetes. Diabetes Care 2010;33:2406-8.

32. Pratley RE, Fleck P, Wilson C. Efficacy and safety of initial combination therapy with alogliptin plus metformin versus either as monotherapy in drugnaive patients with type 2 diabetes: a randomized, double-blind, 6-month study. Diabetes Obes Metab 2014;16:613-21.

33. DeFronzo RA, Burant CF, Fleck P, et al. Efficacy and tolerability of the DPP-4 inhibitor alogliptin combined with pioglitazone, in metformin-treated patients with type 2 diabetes. 7 Clin Endocrinol Metab 2012;97:1615-22.

34. Mita T, Katakami N, Yoshii H, et al.; Collaborators on the Study of Preventive Effects of Alogliptin on Diabetic Atherosclerosis (SPEAD-A) Trial. Alogliptin, a dipeptidyl peptidase 4 inhibitor, prevents the progression of carotid atherosclerosis in patients with type 2 diabetes: the study of preventive effects of alogliptin on diabetic atherosclerosis (SPEAD-A). Diabetes Care 2016;39:139-48.

35. Gomis R, Espadero RM, Jones R, et al. Efficacy and safety of initial combination therapy with linagliptin and pioglitazone in patients with inadequately controlled type 2 diabetes: a randomized, double-blind, placebo-controlled study. Diabetes Obes Metab 2011;13:653-61.

36. Haak T, Meinicke T, Jones R, et al. Initial combination of linagliptin and metformin improves glycaemic control in type 2 diabetes: a randomized, double-blind, placebo-controlled study. Diabetes Obes Metab 2012;14:565-74.

37. Haak T, Meinicke T, Jones R, et al. Initial combination of linagliptin and metformin in patients with type 2 diabetes: efficacy and safety in a randomised, double-blind 1-year extension study. Int 7 Clin Pract 2013;67:1283-93.

38. Owens DR, Swallow R, Dugi KA, et al. Efficacy and safety of linagliptin in persons with type 2 diabetes inadequately controlled by a combination of metformin and sulphonylurea: a 24-week randomized study. Diabet Med 2011;28:1352-61.

39. Taskinen MR, Rosenstock J, Tamminen I, et al. Safety and efficacy of linagliptin as add-on therapy to metformin in patients with type 2 diabetes: a randomized, double-blind, placebo-controlled study. Diabetes Obes Metab 2011;13:65-74.

40. Thrasher J, Daniels K, Patel S, et al. Efficacy and safety of linagliptin in black/African American patients with type 2 diabetes: a 6-month, randomized, double-blind, placebo-controlled study. Endocr Pract 2014;20:412-20.

41. Thrasher J, Daniels K, Patel S, et al. Black/African American patients with type 2 diabetes mellitus: study design and baseline patient characteristics from a randomized clinical trial of linagliptin. Expert Opin Pharmacother 2012;13:2443-52.

42. Barnett AH, Huisman H, Jones R, et al. Linagliptin for patients aged 70 years or older with type 2 diabetes inadequately controlled with common antidiabetes treatments: a randomised, double-blind, placebo-controlled trial. Lancet 2013;382:1413-23.

43. Bajaj M, Gilman R, Patel S, et al. Linagliptin improved glycaemic control without weight gain or hypoglycaemia in patients with type 2 diabetes inadequately controlled by a combination of metformin and pioglitazone: a 24-week randomized, double-blind study. Diabet Med 2014;31:1505-14.

44. Del Prato S, Barnett AH, Huisman H, et al. Effect of linagliptin monotherapy on glycaemic control and markers of beta-cell function in patients with inadequately controlled type 2 diabetes: a randomized controlled trial. Diabetes Obes Metab 2011;13:258-67.

45. McGill JB, Sloan L, Newman J, et al. Long-term efficacy and safety of linagliptin in patients with type 2 diabetes and severe renal impairment: a 1-year, randomized, double-blind, placebo-controlled study. Diabetes Care 2013; 36:237-44.

46. Yki-Järvinen H, Rosenstock J, Durán-Garcia S, et al. Effects of adding linagliptin to basal insulin regimen for inadequately controlled type 2 diabetes: a $\geq 52$-week randomized, double-blind study. Diabetes Care 2013;36:3875-81.

47. 30 week parallel group comparison study of linagliptin + pioglitazone $(5+15,5+30$ and $5+45 \mathrm{mg}$ ) qd versus respective monotherapies, followed by a comparison of $5 \mathrm{mg}+30 \mathrm{mg}$ and $5 \mathrm{mg}+45 \mathrm{mg}$ versus respective monotherapies in type 2 diabetes for up to 54 weeks. ClinicalTrials.gov trial no. NCT01183013; 2015. Available: https://clinicaltrials.gov/ct2/show/NCT01183013 (accessed 2015 June 29).

48. Chen Y, Ning G, Wang C, et al. Efficacy and safety of linagliptin monotherapy in Asian patients with inadequately controlled type 2 diabetes mellitus: A multinational, 24-week, randomized, clinical trial. 7 Diabetes Investig 2015;6:692-8.

49. Efficacy and safety study of linagliptin ( $5 \mathrm{mg}$ administered orally once daily) over 24 weeks in type 2 diabetic patients with insufficient glycaemic control despite metformin therapy. ClinicalTrials.gov trial no. NCT01215097; 2015. Available: https://clinicaltrials.gov/ct2/show/NCT01215097 (accessed 2015 June 29).

50. DeFronzo RA, Lewin A, Patel S, et al. Combination of empagliflozin and linagliptin as second-line therapy in subjects with type 2 diabetes inadequately controlled on metformin [published erratum in Diabetes Care 2015;38:1173]. Diabetes Care 2015;38:384-93

51. Lewin A, DeFronzo RA, Patel S, et al. Initial combination of empagliflozin and linagliptin in subjects with type 2 diabetes [published erratum in Diabetes Care 2015;38:1173]. Diabetes Care 2015;38:394-402.
52. Study to compare the efficacy and safety of administration of the fix dose combination of linagliptin plus metformin in drug naïve type 2 patients. ClinicalTrials.gov trial no. NCT01708902; 2015. Available: https://clinicaltrials.gov/ ct2/show/NCT01708902 (accessed 2015 June 29).

53. Wu W, Li Y, Chen X, et al. Effect of linagliptin on glycemic control in Chinese patients with newly-diagnosed, drug-Naïve type 2 diabetes mellitus: a randomized controlled trial. Med Sci Monit 2015;21:2678-84.

54. Linagliptin as add on therapy to empagliflozin $10 \mathrm{mg}$ or $25 \mathrm{mg}$ with background metformin in patient with type 2 diabetes. ClinicalTrials.gov trial no. NCT01778049; 2016. Available: https://clinicaltrials.gov/ct2/show/ NCT01778049 (accessed 2016 Aug. 24).

55. Pfützner A, Paz-Pacheco E, Allen E, et al.; CV181039 Investigators. Initial combination therapy with saxagliptin and metformin provides sustained glycaemic control and is well tolerated for up to 76 weeks. Diabetes Obes Metab 2011;13:567-76.

56. Jadzinsky M, Pfützner A, Paz-Pacheco E, et al.; CV181-039 Investigators. Saxagliptin given in combination with metformin as initial therapy improves glycaemic control in patients with type 2 diabetes compared with either monotherapy: a randomized controlled trial. Diabetes Obes Metab 2009;11:611-22.

57. Barnett AH, Charbonnel B, Li J, et al. Saxagliptin add-on therapy to insulin with or without metformin for type 2 diabetes mellitus: 52 -week safety and efficacy. Clin Drug Investig 2013;33:707-17.

58. Chacra AR, Tan GH, Ravichandran S, et al.; CV181040 Investigators. Safety and efficacy of saxagliptin in combination with submaximal sulphonylurea versus up-titrated sulphonylurea over 76 weeks. Diab Vasc Dis Res 2011;8:150-9.

59. DeFronzo RA, Hissa MN, Garber AJ, et al.; Saxagliptin 014 Study Group. The efficacy and safety of saxagliptin when added to metformin therapy in patients with inadequately controlled type 2 diabetes with metformin alone. Diabetes Care 2009;32:1649-55.

60. Rosenstock J, Gross JL, Aguilar-Salinas C, et al. Long-term 4-year safety of saxagliptin in drug-naive and metformin-treated patients with type 2 diabetes. Diabet Med 2013;30:1472-6.

61. Frederich R, McNeill R, Berglind N, et al. The efficacy and safety of the dipeptidyl peptidase-4 inhibitor saxagliptin in treatment-naive patients with type 2 diabetes mellitus: a randomized controlled trial. Diabetol Metab Syndr 2012;4:36.

62. Hollander PL, Li J, Frederich R, et al.; CV181013 Investigators. Safety and efficacy of saxagliptin added to thiazolidinedione over 76 weeks in patients with type 2 diabetes mellitus. Diab Vasc Dis Res 2011;8:125-35.

63. Nowicki M, Rychlik I, Haller H, et al. Long-term treatment with the dipeptidyl peptidase- 4 inhibitor saxagliptin in patients with type 2 diabetes mellitus and renal impairment: a randomised controlled 52-week efficacy and safety study. Int 7 Clin Pract 2011;65:1230-9.

64. Pan CY, Yang W, Tou C, et al. Efficacy and safety of saxagliptin in drugnaive Asian patients with type 2 diabetes mellitus: a randomized controlled trial. Diabetes Metab Res Rev 2012;28:268-75.

65. Rosenstock J, Aguilar-Salinas C, Klein E, et al.; CV181-011 Study Investigators. Effect of saxagliptin monotherapy in treatment-naïve patients with type 2 diabetes. Curr Med Res Opin 2009;25:2401-11.

66. Moses RG, Kalra S, Brook D, et al. A randomized controlled trial of the efficacy and safety of saxagliptin as add-on therapy in patients with type 2 diabetes and inadequate glycaemic control on metformin plus a sulphonylurea. Diabetes Obes Metab 2014;16:443-50.

67. Rosenstock J, Hansen L, Zee P, et al. Dual add-on therapy in type 2 diabetes poorly controlled with metformin monotherapy: a randomized double-blind trial of saxagliptin plus dapagliflozin addition versus single addition of saxagliptin or dapagliflozin to metformin. Diabetes Care 2015;38:376-83.

68. Matthaei S, Catrinoiu D, Celiński A, et al. Randomized, double-blind trial of triple therapy with saxagliptin add-on to dapagliflozin plus metformin in patients with type 2 diabetes. Diabetes Care 2015;38:2018-24.

69. Charbonnel B, Karasik A, Liu J, et al.; Sitagliptin Study 020 Group. Efficacy and safety of the dipeptidyl peptidase-4 inhibitor sitagliptin added to ongoing metformin therapy in patients with type 2 diabetes inadequately controlled with metformin alone. Diabetes Care 2006;29:2638-43.

70. Hermansen K, Kipnes M, Luo E, et al.; Sitagliptin Study 035 Group. Efficacy and safety of the dipeptidyl peptidase- 4 inhibitor, sitagliptin, in patients with type 2 diabetes mellitus inadequately controlled on glimepiride alone or on glimepiride and metformin. Diabetes Obes Metab 2007;9:733-45.

71. Henry RR, Staels B, Fonseca VA, et al. Efficacy and safety of initial combination treatment with sitagliptin and pioglitazone - A factorial study. Diabetes Obes Metab 2014;16:223-30.

72. Raz I, Chen Y, Wu M, et al. Efficacy and safety of sitagliptin added to ongoing metformin therapy in patients with type 2 diabetes. Curr Med Res Opin 2008;24:537-50.

73. Vilsbøll T, Rosenstock J, Yki-Järvinen H, et al. Efficacy and safety of sitagliptin when added to insulin therapy in patients with type 2 diabetes. Diabetes Obes Metab 2010;12:167-77.

74. Williams-Herman D, Johnson J, Teng R, et al. Efficacy and safety of sitagliptin and metformin as initial combination therapy and as monotherapy over 2 years in patients with type 2 diabetes. Diabetes Obes Metab 2010;12:442-51.

75. Goldstein BJ, Feinglos MN, Lunceford JK, et al.; Sitagliptin 036 Study Group. Effect of initial combination therapy with sitagliptin, a dipeptidyl 
peptidase-4 inhibitor, and metformin on glycemic control in patients with type 2 diabetes. Diabetes Care 2007;30:1979-87.

76. Yoon KH, Steinberg H, Teng R, et al. Efficacy and safety of initial combination therapy with sitagliptin and pioglitazone in patients with type 2 diabetes: a 54-week study. Diabetes Obes Metab 2012;14:745-52.

77. Yoon KH, Shockey GR, Teng R, et al. Effect of initial combination therapy with sitagliptin, a dipeptidyl peptidase-4 inhibitor, and pioglitazone on glycemic control and measures of beta-cell function in patients with type 2 diabetes. Int 7 Clin Pract 2011;65:154-64.

78. Evaluate saxagliptin in adult Indian patients with type 2 diabetes inadequate glycemic control. ClinicalTrials.gov trial no. NCT00918879; 2011. Available: https://clinicaltrials.gov/ct2/show/NCT00918879 (accessed 2015 July 3).

79. Yang W, Pan CY, Tou C, et al. Efficacy and safety of saxagliptin added to metformin in Asian people with type 2 diabetes mellitus: a randomized controlled trial. Diabetes Res Clin Pract 2011;94:217-24.

80. Study to assess the efficacy and safety of sitagliptin added to the regimen of patients with type 2 diabetes mellitus with inadequate glycemic control on metformin (0431-189). ClinicalTrials.gov trial no. NCT00875394; 2015. Available: https://clinicaltrials.gov/ct2/show/NCT00875394 (accessed 2015 July 3).

81. Barzilai N, Guo H, Mahoney EM, et al. Efficacy and tolerability of sitagliptin monotherapy in elderly patients with type 2 diabetes: a randomized, doubleblind, placebo-controlled trial. Curr Med Res Opin 2011;27:1049-58.

82. Yang W, Guan Y, Shentu Y, et al. The addition of sitagliptin to ongoing metformin therapy significantly improves glycemic control in Chinese patients with type 2 diabetes. 7 Diabetes 2012;4:227-37.

83. Rosenstock J, Brazg R, Andryuk PJ, et al.; Sitagliptin Study 019 Group. Efficacy and safety of the dipeptidyl peptidase- 4 inhibitor sitagliptin added to ongoing pioglitazone therapy in patients with type 2 diabetes: a 24-week, multicenter, randomized, double-blind, placebo-controlled, parallel-group study. Clin Ther 2006;28:1556-68.

84. Aschner P, Kipnes MS, Lunceford JK, et al.; Sitagliptin Study 021 Group. Effect of the dipeptidyl peptidase-4 inhibitor sitagliptin as monotherapy on glycemic control in patients with type 2 diabetes. Diabetes Care 2006;29:2632-7.

85. Fonseca V, Staels B, Morgan JD II, et al. Efficacy and safety of sitagliptin added to ongoing metformin and pioglitazone combination therapy in a randomized, placebo-controlled, 26 -week trial in patients with type 2 diabetes. $\mathcal{F}$ Diabetes Complications 2013;27:177-83.

86. Olansky L, Reasner C, Seck TL, et al. A treatment strategy implementing combination therapy with sitagliptin and metformin results in superior glycaemic control versus metformin monotherapy due to a low rate of addition of antihyperglycaemic agents. Diabetes Obes Metab 2011;13:841-9.

87. Beta-cell function and sitagliptin trial (BEST). ClinicalTrials.gov trial no. NCT00420511; 2011. Available: https://clinicaltrials.gov/ct2/show/ NCT00420511 (accessed 2015 July 3).

88. Dobs AS, Goldstein BJ, Aschner P, et al. Efficacy and safety of sitagliptin added to ongoing metformin and rosiglitazone combination therapy in a randomized placebo-controlled 54-week trial in patients with type 2 diabetes. 7 Diabetes 2013;5:68-79.

89. Moses RG, Round E, Shentu Y, et al. A randomized clinical trial evaluating the safety and efficacy of sitagliptin added to the combination of sulfonylurea and metformin in patients with type 2 diabetes mellitus and inadequate glycemic control. 7 Diabetes 2016;8:701-11

90. Lavalle-González FJ, Januszewicz A, Davidson J, et al. Efficacy and safety of canagliflozin compared with placebo and sitagliptin in patients with type 2 diabetes on background metformin monotherapy: a randomised trial. Diabetologia 2013;56:2582-92

91. Mathieu C, Shankar RR, Lorber D, et al. A randomized clinical trial to evaluate the efficacy and safety of co-administration of sitagliptin with intensively titrated insulin glargine. Diabetes Ther 2015;6:127-42.

92. Roden M, Weng J, Eilbracht J, et al.; EMPA-REG MONO trial investigators. Empagliflozin monotherapy with sitagliptin as an active comparator in patients with type 2 diabetes: a randomised, double-blind, placebo-controlled, phase 3 trial. Lancet Diabetes Endocrinol 2013;1:208-19.

93. Clinical trial to evaluate the safety and efficacy of the addition of sitagliptin in participants with type 2 diabetes mellitus receiving acarbose monotherapy (MK-0431-130). ClinicalTrials.gov trial no. NCT01177384; 2015. Available: https://clinicaltrials.gov/ct2/show/NCT01177384 (accessed 2015 July 6).

94. Skrivanek Z, Gaydos BL, Chien JY, et al. Dose-finding results in an adaptive, seamless, randomized trial of once-weekly dulaglutide combined with metformin in type 2 diabetes patients (AWARD-5). Diabetes Obes Metab 2014;16:748-56.

95. Efficacy and safety of albiglutide in treatment of type 2 diabetes. ClinicalTrials. gov trial no. NCT00838903; 2014. Available: https://clinicaltrials.gov/ct2/ show/NCT00838903 (accessed 2015 July 6).

96. Ji L, Han P, Wang X, et al. Randomized clinical trial of the safety and efficacy of sitagliptin and metformin co-administered to Chinese patients with type 2 diabetes mellitus. 7 Diabetes Investig 2016;7:727-36.

97. Treatment intensification with biphasic insulin aspart 30 in subjects with type 2 diabetes inadequately controlled on sitagliptin and metformin (SIT2MIX). Clinical Trials.gov trial no. NCT01519674; 2014. Available: https://clinicaltrials.gov/ct2/ show/NCT01519674?term=NCT01519674\&rank=1 (accessed 2015 July 6).

98. A study in China evaluating the safety and efficacy of adding sitagliptin to stable therapy with sulfonylurea with or without metformin in participants with type 2 diabetes mellitus (T2DM) (MK-0431-253). ClinicalTrials.gov trial no. NCT01590771; 2015. Available: https://clinicaltrials.gov/ct2/show/NCT015 90771?term=NCT01590771\&rank=1 (accessed 2015 July 6)

99. A study in China evaluating the safety and efficacy of adding sitagliptin to stable therapy with insulin with or without metformin in participants with type 2 diabetes mellitus (T2DM) (MK-0431-254). ClinicalTrials.gov trial no. NCT01590797; 2015. Available: https://clinicaltrials.gov/ct2/show/NCT015 90797? term=NCT01590797\& $\mathrm{rank}=1$ (accessed 2015 July 6).

100. Comparison study of the glycemic effects, safety, and tolerability of exenatide once weekly suspension to sitagliptin and placebo in subjects with type 2 diabetes mellitus (DURATION-NEO-2). ClinicalTrials.gov trial no. NCT01652729; 2015. Available: https://clinicaltrials.gov/ct2/show/NCT01652729? term=NCT0 $1652729 \&$ rank=1 (accessed 2015 July 6)

101. Ishikawa S, Shimano M, Watarai M, et al. Impact of sitagliptin on carotid intima-media thickness in patients with coronary artery disease and impaired glucose tolerance or mild diabetes mellitus. Am $\mathcal{7}$ Cardiol 2014;114:384-8.

102. Derosa G, Carbone A, D'Angelo A, et al. A randomized, double-blind, placebocontrolled trial evaluating sitagliptin action on insulin resistance parameters and $\beta$-cell function. Expert Opin Pharmacother 2012;13:2433-42.

103. Derosa G, Carbone A, D'Angelo A, et al. Variations in inflammatory biomarkers following the addition of sitagliptin in patients with type 2 diabetes not controlled with metformin. Intern Med 2013;52:2179-87.

104. Derosa G, Carbone A, Franzetti I, et al. Effects of a combination of sitagliptin plus metformin vs metformin monotherapy on glycemic control, $\beta$-cell function and insulin resistance in type 2 diabetic patients. Diabetes Res Clin Pract 2012;98:51-60.

105. Derosa G, Ragonesi PD, Fogari E, et al. Sitagliptin added to previously taken antidiabetic agents on insulin resistance and lipid profile: a 2-year study evaluation. Fundam Clin Pharmacol 2014;28:221-9.

106. Chien MN, Lee CC, Chen WC, et al. Effect of sitagliptin as add-on therapy in elderly type 2 diabetes patients with inadequate glycemic control in Taiwan. Int 7 Gerontol 2011;5:103-6.

107. Weinstock RS, Guerci B, Umpierrez G, et al. Safety and efficacy of onceweekly dulaglutide versus sitagliptin after 2 years in metformin-treated patients with type 2 diabetes (AWARD-5): a randomized, phase III study. Diabetes Obes Metab 2015;17:849-58.

108. Mita T, Katakami N, Shiraiwa T, et al.; Collaborators on the Sitagliptin Preventive Study of Intima-Media Thickness Evaluation (SPIKE) Trial. Sitagliptin attenuates the progression of carotid intima-media thickening in insulin-treated patients with type 2 diabetes: the sitagliptin preventive study of intima-media thickness evaluation (SPIKE): a randomized controlled trial. Diabetes Care 2016;39:455-64.

109. Omarigliptin (MK-3102) clinical trial - Placebo- and sitagliptin-controlled monotherapy study in Japanese patients with type 2 diabetes mellitus (MK3102-020). ClinicalTrials.gov trial no. NCT01703221; 2016. Available: https://clinicaltrials.gov/ct2/show/NCT01703221 (accessed 2016 Aug. 24).

110. Bosi E, Camisasca RP, Collober C, et al. Effects of vildagliptin on glucose control over 24 weeks in patients with type 2 diabetes inadequately controlled with metformin. Diabetes Care 2007;30:890-5.

111. Bosi E, Dotta F, Jia Y, et al. Vildagliptin plus metformin combination therapy provides superior glycaemic control to individual monotherapy in treatmentnaive patients with type 2 diabetes mellitus. Diabetes Obes Metab 2009;11:506-15.

112. Fonseca V, Schweizer A, Albrecht D, et al. Addition of vildagliptin to insulin improves glycaemic control in type 2 diabetes. Diabetologia 2007;50:1148-55.

113. Krum H, Lukashevich V, Bolli GB, et al. No significant difference in risk of heart failure hospitalization with vildagliptin in diabetic patients with systolic chronic heart failure: VIVIDD study. Diabetes 2014;63:A265.

114. Scherbaum WA, Schweizer A, Mari A, et al. Efficacy and tolerability of vildagliptin in drug-naïve patients with type 2 diabetes and mild hyperglycaemia. Diabetes Obes Metab 2008;10:675-82.

115. Scherbaum WA, Schweizer A, Mari A, et al. Evidence that vildagliptin attenuates deterioration of glycaemic control during 2-year treatment of patients with type 2 diabetes and mild hyperglycaemia. Diabetes Obes Metab 2008;10:1114-24.

116. Strain WD, Lukashevich V, Kothny W, et al. Individualised treatment targets for elderly patients with type 2 diabetes using vildagliptin add-on or lone therapy (INTERVAL): a 24 week, randomised, double-blind, placebo-controlled study. Lancet 2013;382:409-16.

117. Vollmer M, Abletshauser C, Pennartz C, et al. Wirksamkeit und Sicherheit der frühen Kombination von Vildagliptin mit Metformin im Vergleich zu Placebo bei Patienten mit Typ 2 Diabetes. Diabetol Stoffwechs 2009;4:239.

118. Garber AJ, Schweizer A, Baron MA, et al. Vildagliptin in combination with pioglitazone improves glycaemic control in patients with type 2 diabetes failing thiazolidinedione monotherapy: a randomized, placebo-controlled study. Diabetes Obes Metab 2007;9:166-74.

119. Garber AJ, Foley JE, Banerji MA, et al. Effects of vildagliptin on glucose control in patients with type 2 diabetes inadequately controlled with a sulphonylurea. Diabetes Obes Metab 2008;10:1047-56.

120. Yang W, Xing X, Lv X, et al. Vildagliptin added to sulfonylurea improves glycemic control without hypoglycemia and weight gain in Chinese patients with type 2 diabetes mellitus. 7 Diabetes 2015;7:174-81.

121. Foley JE, Bunck MC, Möller-Goede DL, et al. Beta cell function following year vildagliptin or placebo treatment and after 12 week washout in drug- 
naive patients with type 2 diabetes and mild hyperglycaemia: a randomised controlled trial. Diabetologia 2011:54:1985-91.

122. Bunck MC, Poelma M, Eekhoff EM, et al. Effects of vildagliptin on postprandial markers of bone resorption and calcium homeostasis in recently diagnosed, well-controlled type 2 diabetes patients. 7 Diabetes 2012;4:181-5.

123. Pan C, Xing X, Han P, et al.; Institution Investigators. Efficacy and tolerability of vildagliptin as add-on therapy to metformin in Chinese patients with type 2 diabetes mellitus. Diabetes Obes Metab 2012;14:737-44.

124. Lukashevich V, Del Prato S, Araga M, et al. Efficacy and safety of vildagliptin in patients with type 2 diabetes mellitus inadequately controlled with dual combination of metformin and sulphonylurea. Diabetes Obes Metab 2014:16:403-9.

125. Macauley M, Hollingsworth KG, Smith FE, et al. Effect of vildagliptin on hepatic steatosis. 7 Clin Endocrinol Metab 2015;100:1578-85.

126. Ahrén B, Gomis R, Standl E, et al. Twelve- and 52-week efficacy of the dipeptidyl peptidase IV inhibitor LAF237 in metformin-treated patients with type 2 diabetes. Diabetes Care 2004;27:2874-80.

127. Áhrén B, Pacini G, Foley JE, et al. Improved meal-related beta-cell function and insulin sensitivity by the dipeptidyl peptidase-IV inhibitor vildagliptin in metformintreated patients with type 2 diabetes over 1 year. Diabetes Care 2005;28:1936-40.

128. Goodman M, Thurston H, Penman J. Efficacy and tolerability of vildagliptin in patients with type 2 diabetes inadequately controlled with metformin monotherapy. Horm Metab Res 2009;41:368-73.

129. Ito M, Abe M, Okada K, et al. The dipeptidyl peptidase-4 (DPP-4) inhibitor vildagliptin improves glycemic control in type 2 diabetic patients undergoing hemodialysis. Endocr 7 2011;58:979-87.

130. Derosa G, Ragonesi PD, Carbone A, et al. Vildagliptin added to metformin on beta-cell function after a euglycemic hyperinsulinemic and hyperglycemic clamp in type 2 diabetes patients. Diabetes Technol Ther 2012;14:475-84.

131. Derosa G, Ragonesi PD, Carbone A, et al. Vildagliptin action on some adipocytokine levels in type 2 diabetic patients: a 12-month, placebo-controlled study. Expert Opin Pharmacother 2012;13:2581-91.

132. Derosa G, Ragonesi PD, Carbone A, et al. Evaluation of the positive effects on insulin-resistance and beta-cell measurements of vildagliptin in addition to metformin in type 2 diabetic patients. Pharmacol Res 2013;73:20-6.

133. Zografou I, Sampanis C, Gkaliagkousi E, et al. Effect of vildagliptin on hsCRP and arterial stiffness in patients with type 2 diabetes mellitus. Hormones (Athens) 2015;14:118-25

134. Yang SJ, Min KW, Gupta SK, et al. A multicentre, multinational, randomized, placebo-controlled, double-blind, phase 3 trial to evaluate the efficacy and safety of gemigliptin (LC15-0444) in patients with type 2 diabetes. Diabetes Obes Metab 2013;15:410-6.

135. Efficacy and safety of MP-513 in combination with metformin in patients with type 2 diabetes. ClinicalTrials.gov trial no. NCT00971243; 2014. Available: https://clinicaltrials.gov/ct2/show/NCT00971243?term=NCT00971243\&rank $=1$ (accessed 2015 July 6)

136. Yang HK, Min KW, Park SW, et al. A randomized, placebo-controlled, double-blind, phase 3 trial to evaluate the efficacy and safety of anagliptin in drug-naive patients with type 2 diabetes. Endocr 7 2015;62:449-62.

137. Efficacy and safety study of linagliptin ( $5 \mathrm{mg}$ administered orally once daily) over 24 weeks, in drug naïve or previously treated type 2 diabetic patients with insufficient glycaemic control. ClinicalTrials.gov trial no. NCT01214239; 2015. Available: https://clinicaltrials.gov/ct2/show/NCT01214239 (accessed 2015 June 29).

138. A study to evaluate the safety and efficacy of sitagliptin $100 \mathrm{mg}$ in participants with type 2 diabetes mellitus who have inadequate glycemic control (MK-0431229). ClinicalTrials.gov trial no. NCT01076075; 2015. Available: https://clinical trials.gov/ct2/show/NCT01076075 (accessed 2015 July 6).

139. Safety and efficacy of co-administration of sitagliptin and metformin in China (MK0431-121). ClinicalTrials.gov trial no. NCT01076088; 2015. Available: https:/clinical trials.gov/ct2/show/NCT01076088?term=NCT01076088\&rank=1 (accessed 2015 July 6).

140. Jin SM, Park SW, Yoon KH, et al. Anagliptin and sitagliptin as add-ons to metformin for patients with type 2 diabetes: a 24-week, multicentre, randomized, double-blind, active-controlled, phase III clinical trial with a 28 -week extension. Diabetes Obes Metab 2015;17:511-5.

141. Phase 3 study to compare the efficacy and safety of gemigliptin and vildagliptin as add-on therapy to metformin in people with type 2 diabetes inadequately controlled with metformin. ClinicalTrials.gov trial no. NCT02343926; 2016. Available: https://clinicaltrials.gov/ct2/show/NCT02343926 (accessed 2016 Aug. 24).

142. Study to evaluate the safety and efficacy of the addition of omarigliptin (MK3102 ) compared with the addition of sitagliptin in participants with type 2 diabetes mellitus with inadequate glycemic control on metformin (MK-3102026). ClinicalTrials.gov trial no. NCT01841697; 2016. Available: https:// clinicaltrials.gov/ct2/show/NCT01841697 (accessed 2016 Aug. 24).

143. A Phase IIIb study to evaluate the safety and efficacy of gemigliptin in type 2 diabetes mellitus patients with moderate or severe renal impairment(GUARD Study) (GUARD). ClinicalTrials.gov trial no. NCT01968044; 2016. Available: https://clinicaltrials.gov/ct2/show/NCT01968044 (accessed 2016 Aug. 24).

144. Tang YZ, Wang G, Jiang ZH, et al. Efficacy and safety of vildagliptin, sitagliptin, and linagliptin as add-on therapy in Chinese patients with T2DM inadequately controlled with dual combination of insulin and traditional oral hypoglycemic agent. Diabetol Metab Syndr 2015;7:91.

145. Galstyan KO, Nedosugova LV, Petunina NA, et al. First Russian DPP-4 inhibitor gosogliptin comparing to vildagliptin in type 2 diabetes mellitus patients. Diabetes Mellitus 2015;19:89-96.

146. Guerci B, Monnier L, Serusclat P, et al. Continuous glucose profiles with vildagliptin versus sitagliptin in add-on to metformin: results from the randomized Optima study. Diabetes Metab 2012;38:359-66.

147. Li CJ, Liu XJ, Bai L, et al. Efficacy and safety of vildagliptin, Saxagliptin or Sitagliptin as add-on therapy in Chinese patients with type 2 diabetes inadequately controlled with dual combination of traditional oral hypoglycemic agents. Diabetol Metab Syndr 2014;6:69.

148. Kothny W, Lukashevich V, Foley JE, et al. Comparison of vildagliptin and sitagliptin in patients with type 2 diabetes and severe renal impairment: a randomised clinical trial. Diabetologia 2015;58:2020-6.

149. Abbas AS, Dehbi HM, Ray KK. Cardiovascular and non-cardiovascular safety of dipeptidyl peptidase- 4 inhibition: a meta-analysis of randomized controlled cardiovascular outcome trials. Diabetes Obes Metab 2016;18:295-9.

150. Kongwatcharapong J, Dilokthornsakul P, Nathisuwan S, et al. Effect of dipeptidyl peptidase- 4 inhibitors on heart failure: a meta-analysis of randomized clinical trials. Int 7 Cardiol 2016;211:88-95.

151. Li L, Li S, Deng K, et al. Dipeptidyl peptidase-4 inhibitors and risk of heart failure in type 2 diabetes: systematic review and meta-analysis of randomised and observational studies. BM7 2016;352:1610.

152. Monami M, Dicembrini I, Mannucci E. Dipeptidyl peptidase-4 inhibitors and heart failure: a meta-analysis of randomized clinical trials. Nutr Metab Cardiovasc Dis 2014;24:689-97.

153. Savarese G, Perrone-Filardi P, D'Amore C, et al. Cardiovascular effects of dipeptidyl peptidase- 4 inhibitors in diabetic patients: a meta-analysis. Int $\mathcal{F}$ Cardiol 2015;181:239-44.

154. Wu S, Hopper I, Skiba M, et al. Dipeptidyl peptidase-4 inhibitors and cardiovascular outcomes: meta-analysis of randomized clinical trials with 55,141 participants. Cardiovasc Ther 2014;32:147-58.

155. Dormandy JA, Charbonnel B, Eckland DJ, et al.; PROactive Investigators. Secondary prevention of macrovascular events in patients with type 2 diabetes in the PROactive Study (PROspective pioglitAzone Clinical Trial In macroVascular Events): a randomised controlled trial. Lancet 2005;366:1279-89.

156. Nissen SE, Wolski K. Effect of rosiglitazone on the risk of myocardial infarction and death from cardiovascular causes. N Engl 7 Med 2007;356:2457-71.

157. Friedrich JO, Beyene J, Adhikari NK. Rosiglitazone: can meta-analysis accurately estimate excess cardiovascular risk given the available data? Re-analysis of randomized trials using various methodologic approaches. BMC Res Notes 2009;2:5.

Competing interests: Subodh Verma has received speaker honoraria and/or grants from Amgen, AstraZeneca, Merck, Novartis, Sanofi, and Valeant. Ronald Goldenberg has received research support from AstraZeneca, Böehringer Ingelheim, Eli Lilly, GlaxoSmithKline, Merck Novartis, Novo Nordisk, Takeda; has served on advisory panels for AstraZeneca, Böehringer Ingelheim, Eli Lilly, Merck, Novo Nordisk, and Takeda; has participated in speaker bureaus for AstraZeneca, Böehringer Ingelheim, Eli Lilly, Merck, and Novo Nordisk and Servier; and has served as a consultant for AstraZeneca, Böehringer Ingelheim, Eli Lilly, Merck, Novo Nordisk and Takeda. Deepak Bhatt discloses the following relationships - Advisory Board: Cardax, Elsevier Practice Update Cardiology, Medscape Cardiology, Regado Biosciences; Board of Directors: Boston VA Research Institute, Society of Cardiovascular Patient Care; Chair: American Heart Association Quality Oversight Committee; Data Monitoring Committees: Duke Clinical Research Institute, Harvard Clinical Research Institute, Mayo Clinic, Population Health Research Institute; Honoraria: American College of Cardiology (Senior Associate Editor, Clinical Trials and News, ACC.org), Belvoir Publications (Editor-in-Chief, Harvard Heart Letter), Duke Clinical Research Institute (clinical trial steering committees), Harvard Clinical Research Institute (clinical trial steering committee), HMP Communications (Editor-in-Chief, Journal of Invasive Cardiology), Journal of the American College of Cardiology (Guest Editor; Associate Editor), Population Health Research Institute (clinical trial steering committee), Slack Publications (Chief Medical Editor, Cardiology Today's Intervention), Society of Cardiovascular Patient Care (Secretary/Treasurer), WebMD (CME steering committees); Other: Clinical Cardiology (Deputy Editor), NCDR-ACTION Registry Steering Committee (Vice-Chair), VA CART Research and Publications Committee (Chair); Research Funding: Amarin, AstraZeneca (including for serving as the co-PI of SAVOR-TIMI 53), Bristol-Myers Squibb, Eisai, Ethicon, Forest Laboratories, Ischemix, Medtronic, Pfizer, Roche, Sanofi Aventis, The Medicines Company; Royalties: Elsevier (Editor, Cardiovascular Intervention: A Companion to Braunwald's Heart Disease); Site Co-Investigator: Biotronik, Boston Scientific, St. Jude Medical; Trustee: American College of Cardiology; Unfunded Research: FlowCo, PLx Pharma, Takeda. Kim Connelly has received support from Astra Zeneca/Bristol Myer Squibb, consultancy fees from Servier, Merck, Janssen and Boehringer Ingelheim, travel support 
from Bristol Myer Squibb and holds a patent with Boehringer Ingelheim for linagliptin and heart failure with preserved ejection fraction. Lawrence Leiter has received research funding from, has provided CME on behalf of, and/or has acted as an advisor to AstraZeneca, Böehringer Ingelheim, Eli Lilly, GlaxoSmithKline, Janssen, Merck, NovoNordisk, Pfizer, Sanofi, and Servier. All other authors have reported that they have no relationships relevant to the contents of this paper to disclose.

Affiliations: Divisions of Cardiac Surgery (Verma, Quan, Teoh), Endocrinology and Metabolism (Teoh, Leiter) and Cardiology (Connelly), and Departments of Surgery (Verma), Medicine (Connelly, Leiter, Friedrich) and Critical Care (Friedrich), Li Ka Shing Knowledge Institute of St. Michael's Hospital; Departments of Surgery (Verma), Medicine (Farkouh, Connelly, Leiter, Friedrich), Nutritional Sciences (Leiter) and Interdepartmental Division of Critical Care (Friedrich), University of Toronto, Toronto, Ont.; LMC Diabetes \& Endocrinology (Goldenberg), Thornhill, Ont.; Brigham and Women's Hospital Heart \& Vascular Center and Harvard Medical School (Bhatt), Boston, Mass.; Peter Munk Cardiac Centre (Farkouh), University Health Network, Toronto, Ont.
Contributors: Subodh Verma, Ronald Goldenberg and Jan Friedrich contributed to the conception, design, acquisition, analysis and interpretation of data, drafted and revised the article. Deepak Bhatt, Michael Farkouh, Kim Connelly and Lawrence Leiter contributed to data interpretation and revised the article critically for important intellectual content. Adrian Quan and Hwee Teoh contributed to the acquisition of data, drafted and revised the article. All of the authors gave final approval to the version to be published and agree to act as guarantors of the work.

Funding: Subodh Verma is the Canada Research Chair (CRC) in Atherosclerosis. Kim Connelly is supported by a New Investigator award from the CIHR. Jan Friedrich is supported by a Clinician-Scientist Award from the Canadian Institutes of Health Research (CIHR). The CRC program and $\mathrm{CIHR}$ had no role in the design and conduct of the study; collection, management, analysis, and interpretation of the data; preparation, review, or approval of the manuscript; and decision to submit the manuscript for publication.

Supplemental information: For reviewer comments and the original submission of this manuscript, please see www.cmajopen.ca/content/5/1/ E152/suppl/DC1

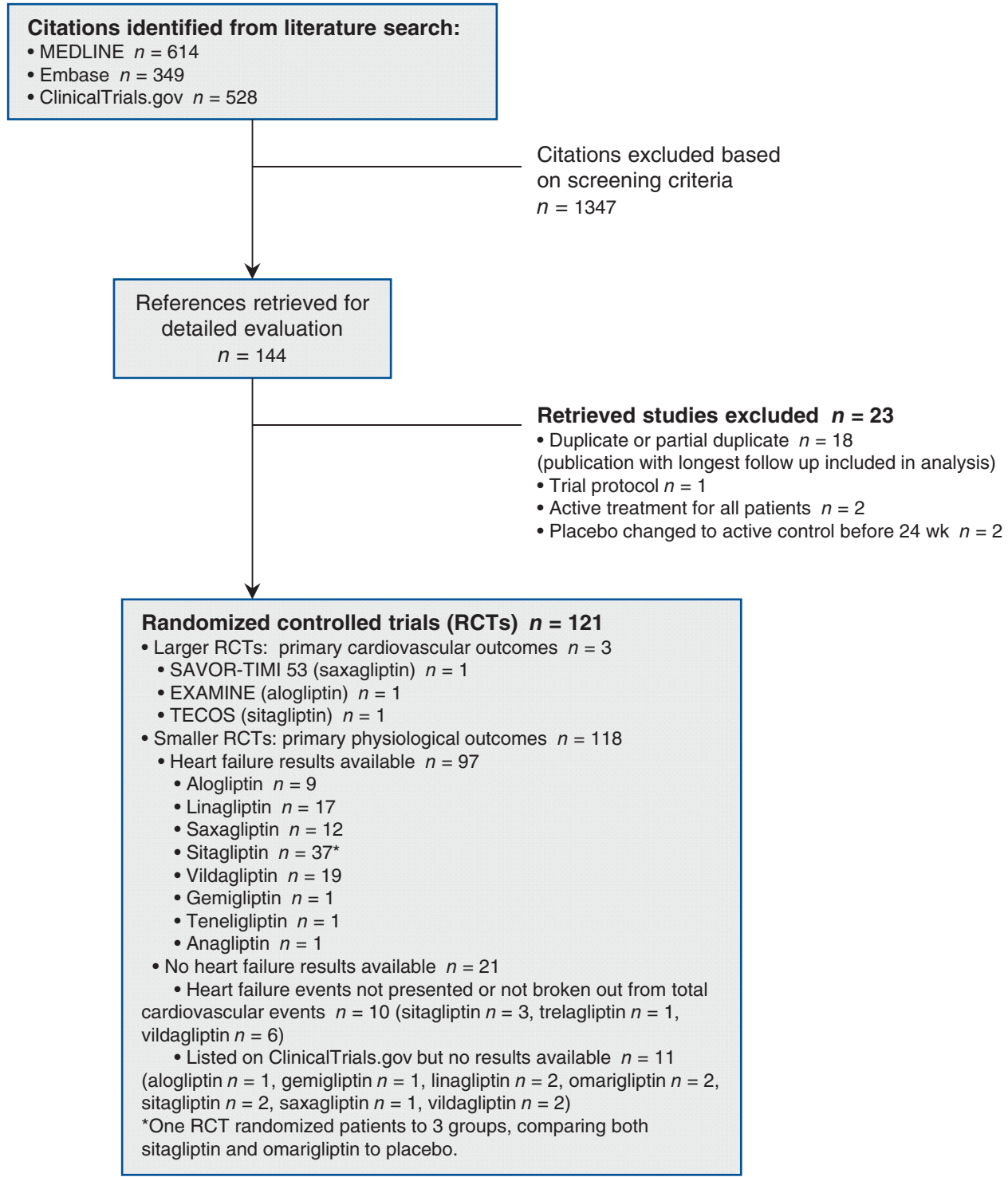

Figure 1: Search strategy and trial flow. 


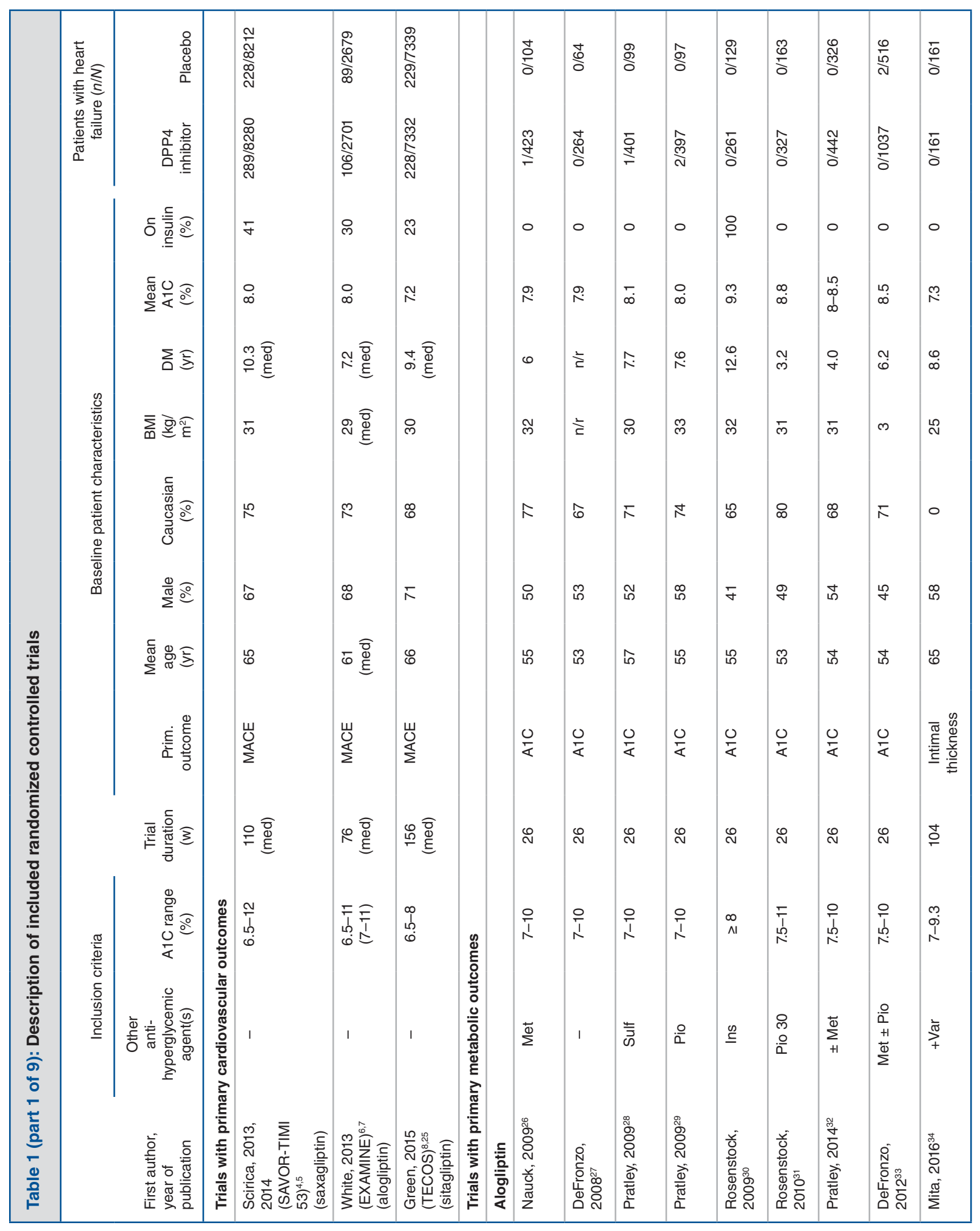




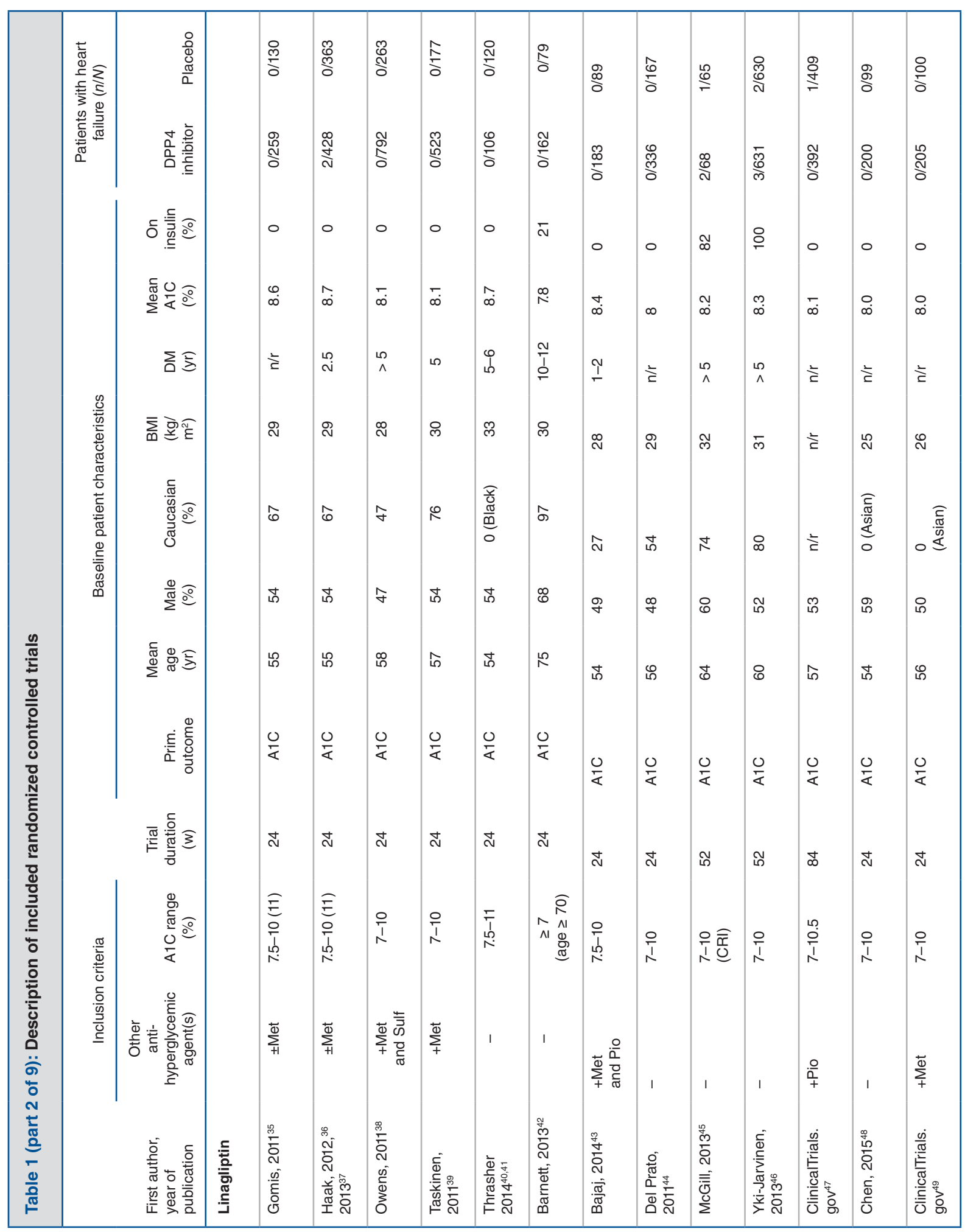




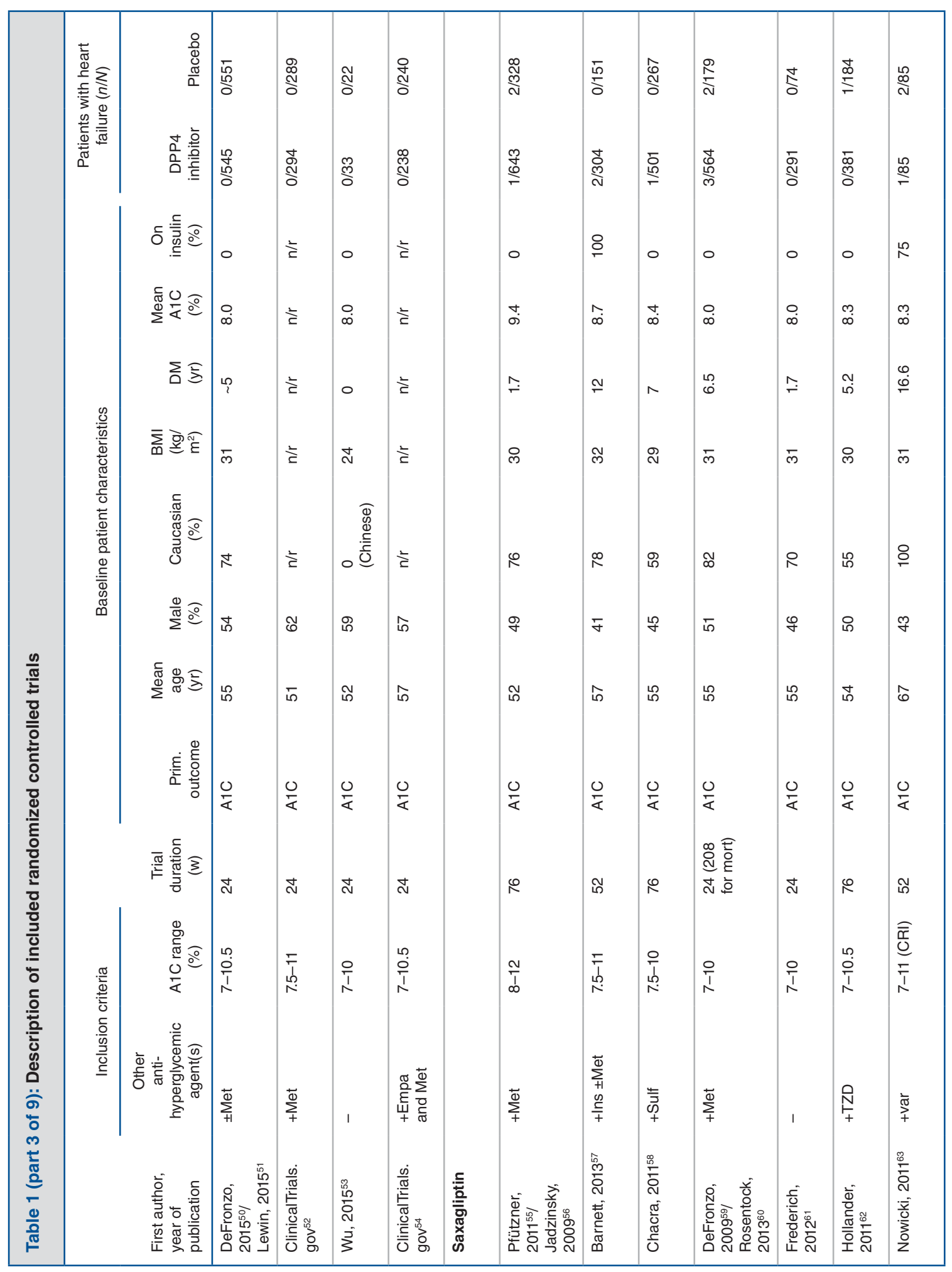




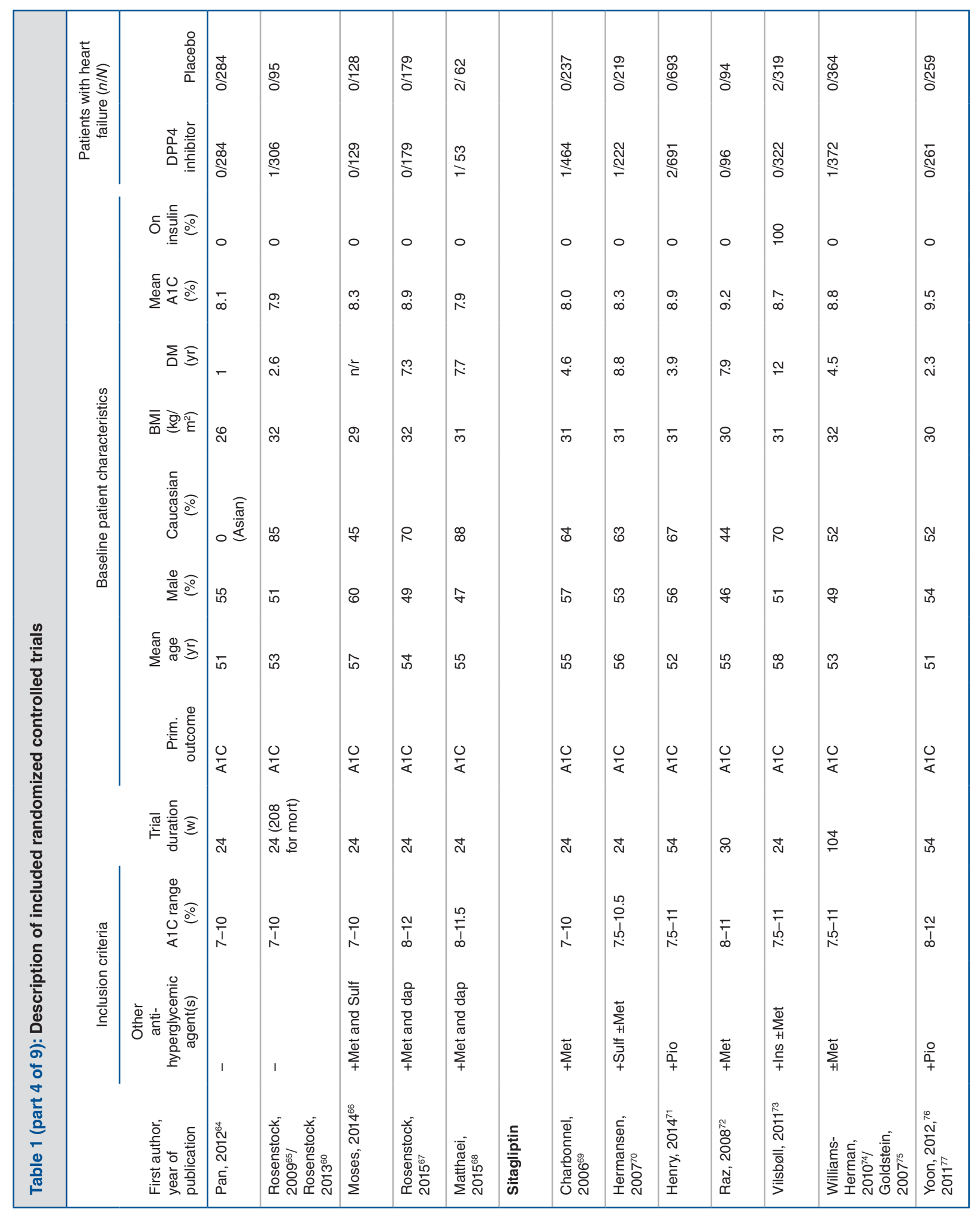




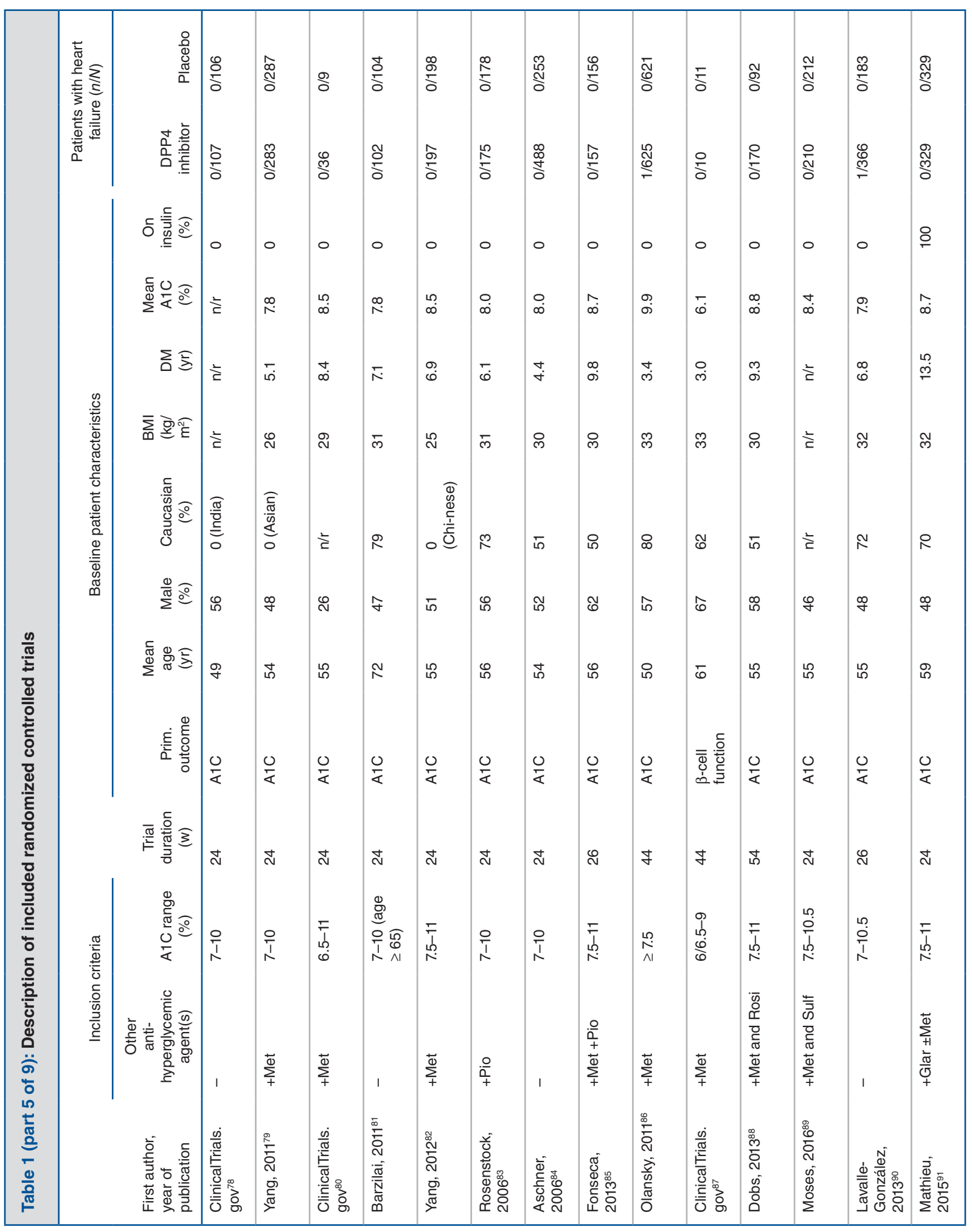




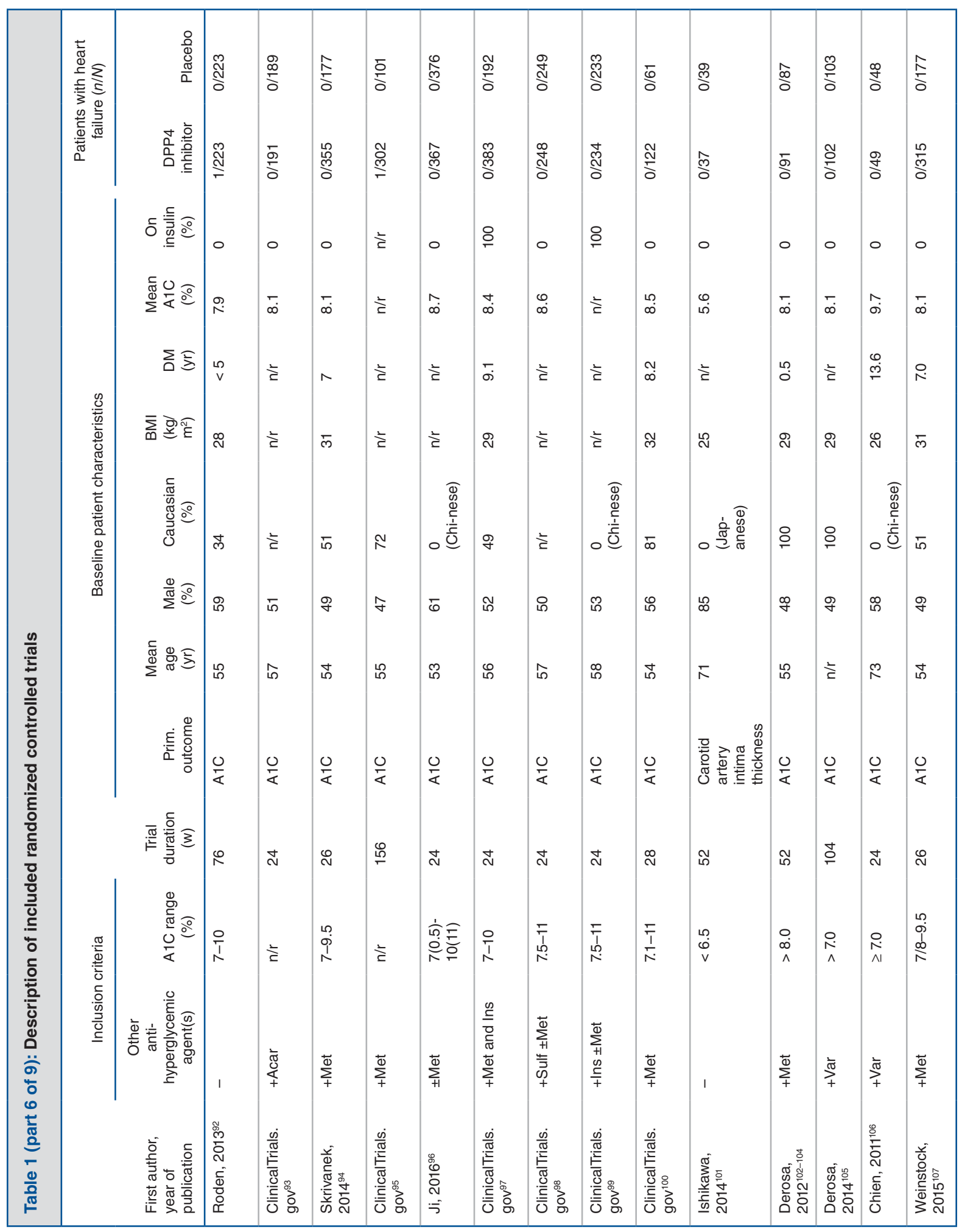




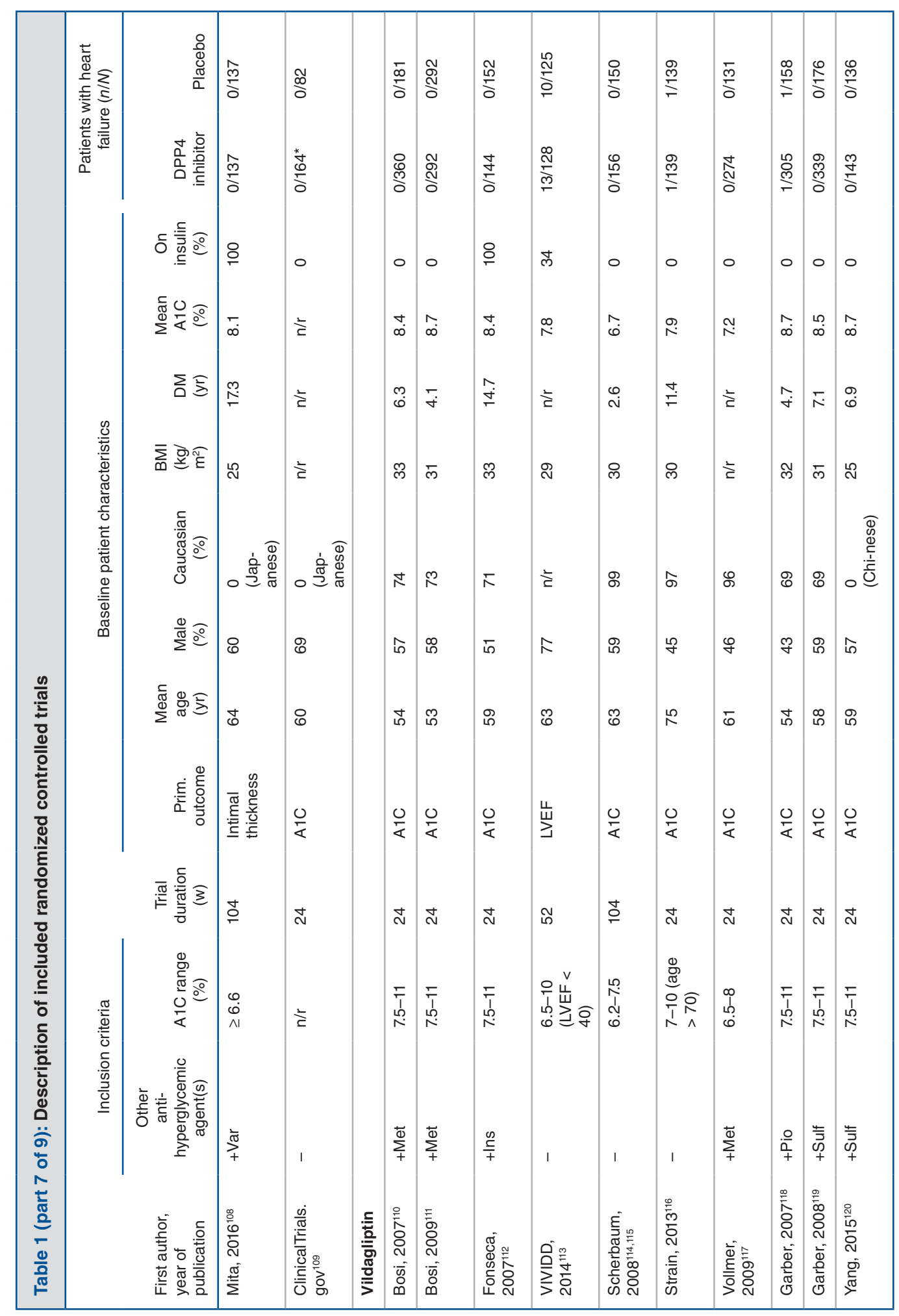




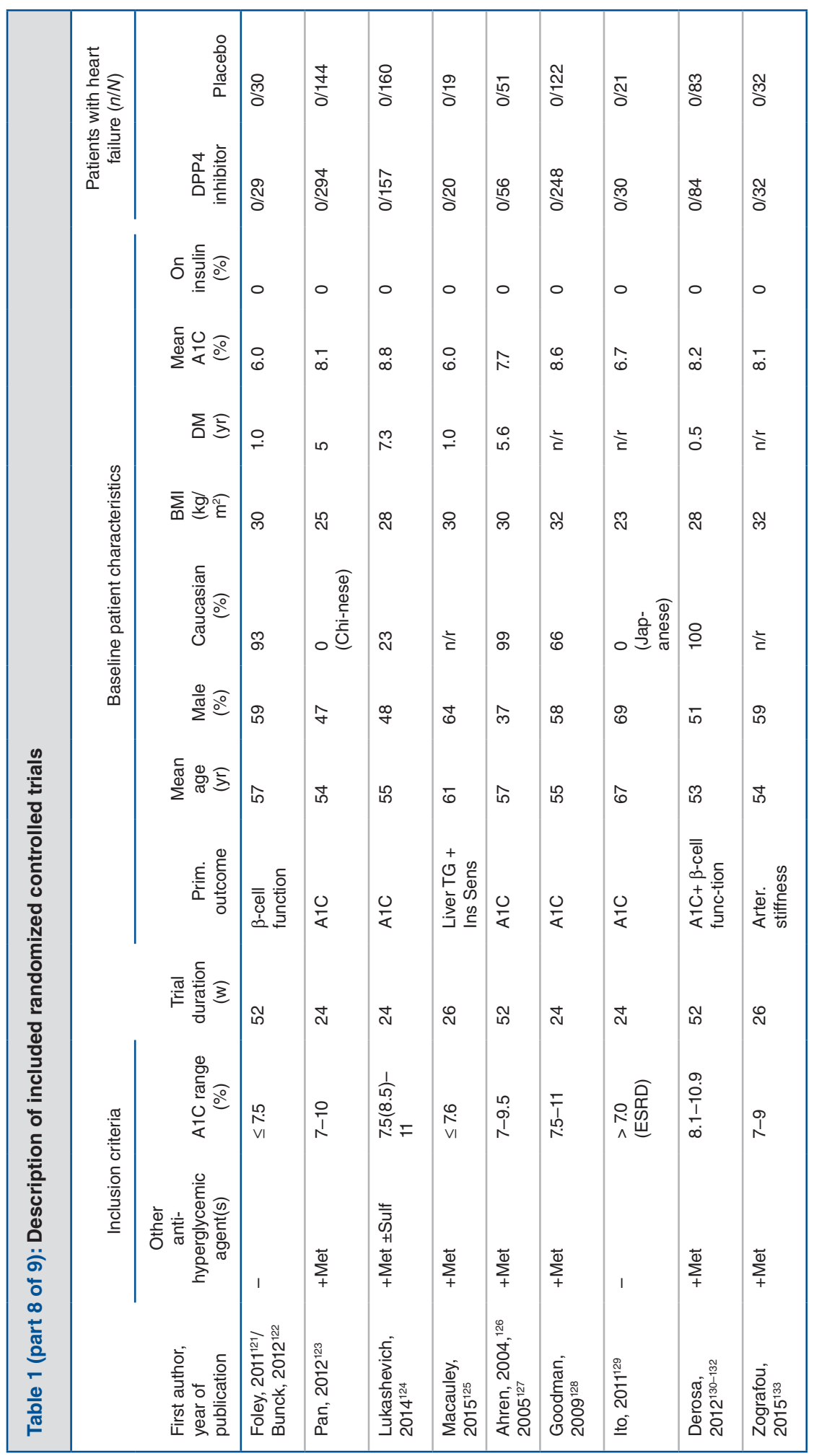




\begin{tabular}{|c|c|c|c|c|c|c|c|c|c|}
\hline 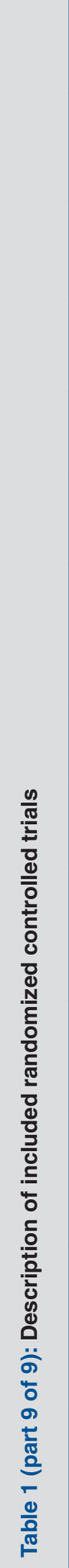 & 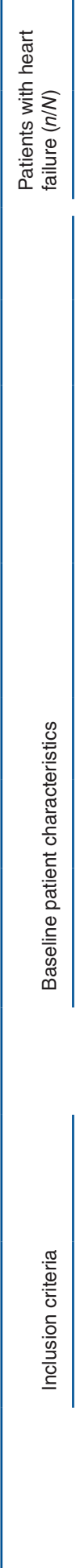 & 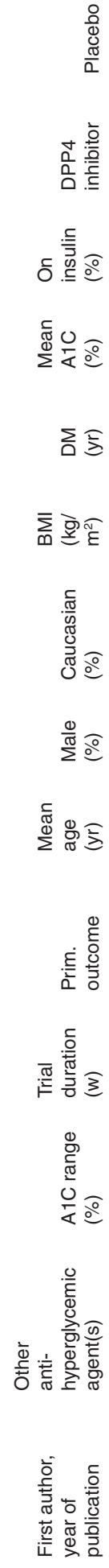 & 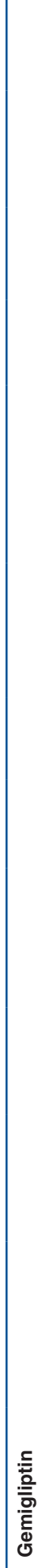 & 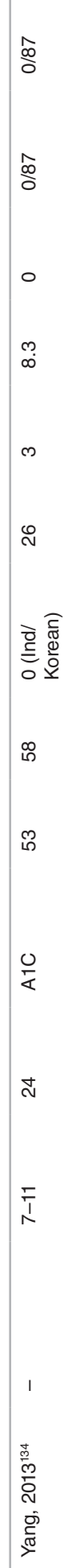 & 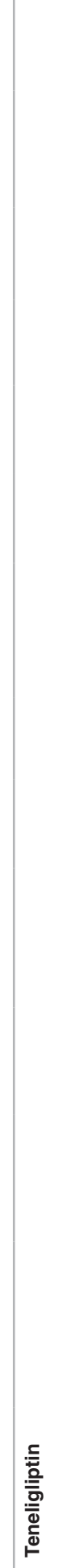 & 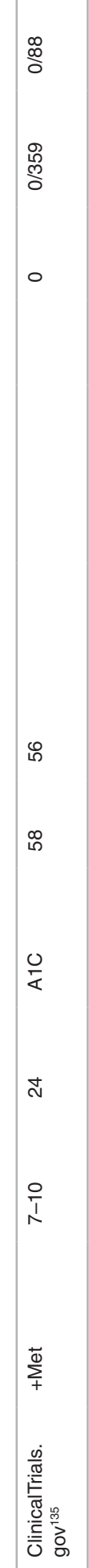 & $\begin{array}{l}\frac{c}{0} \\
\frac{\bar{z}}{\overline{7}} \\
\frac{\sigma}{4} \\
\frac{\sigma}{4}\end{array}$ & 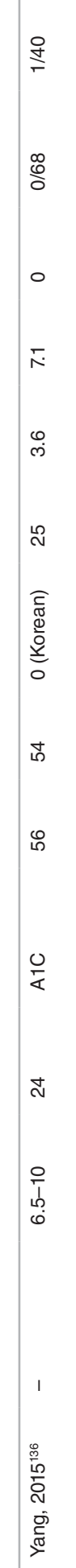 & 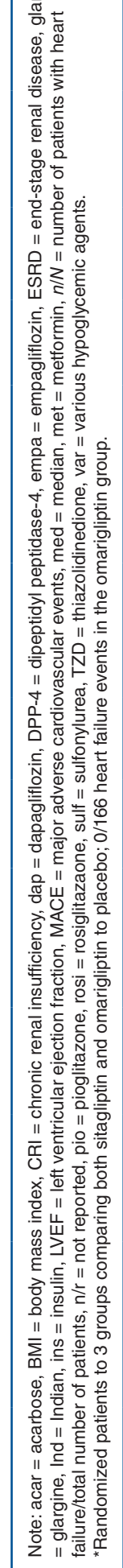 \\
\hline
\end{tabular}




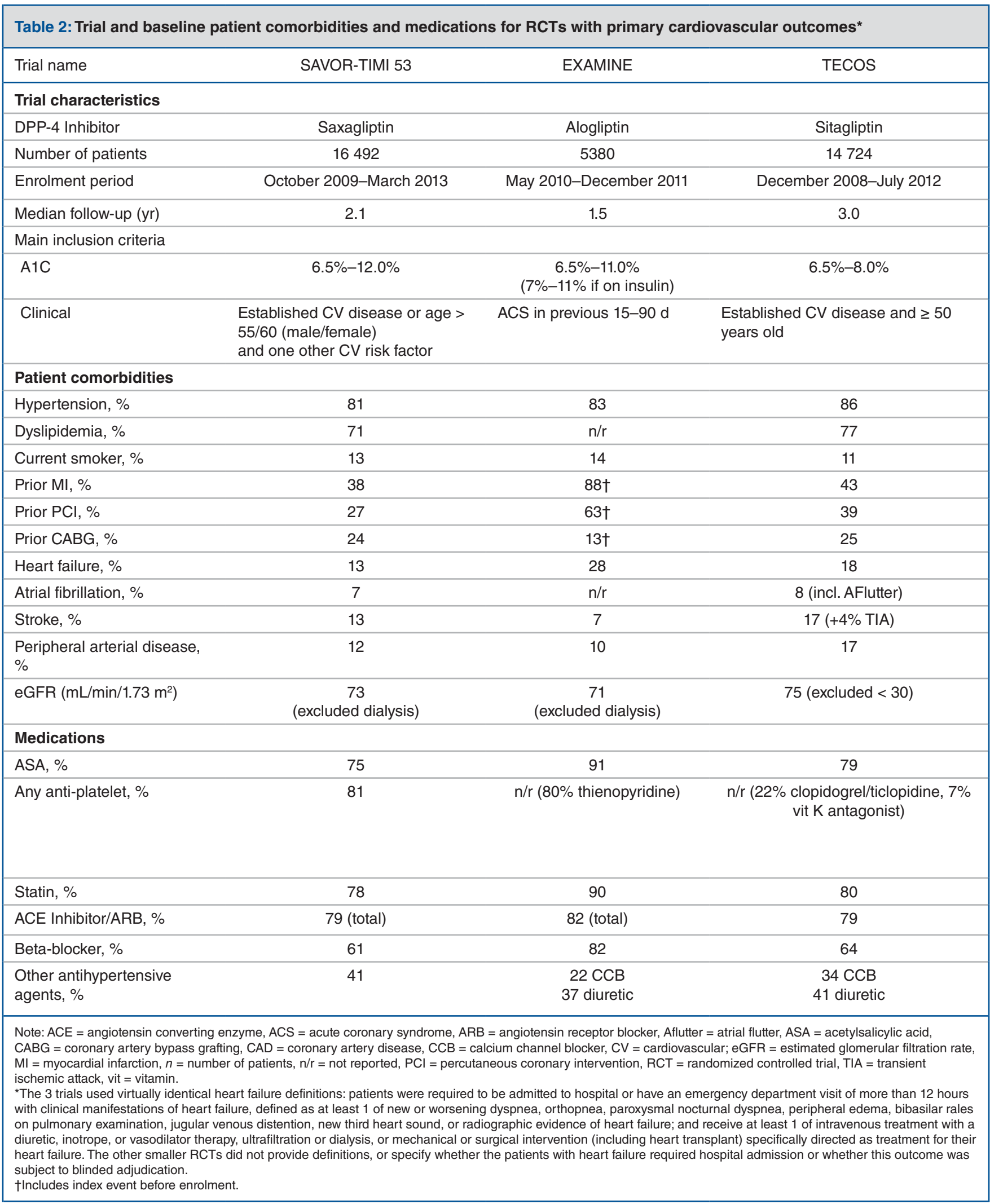




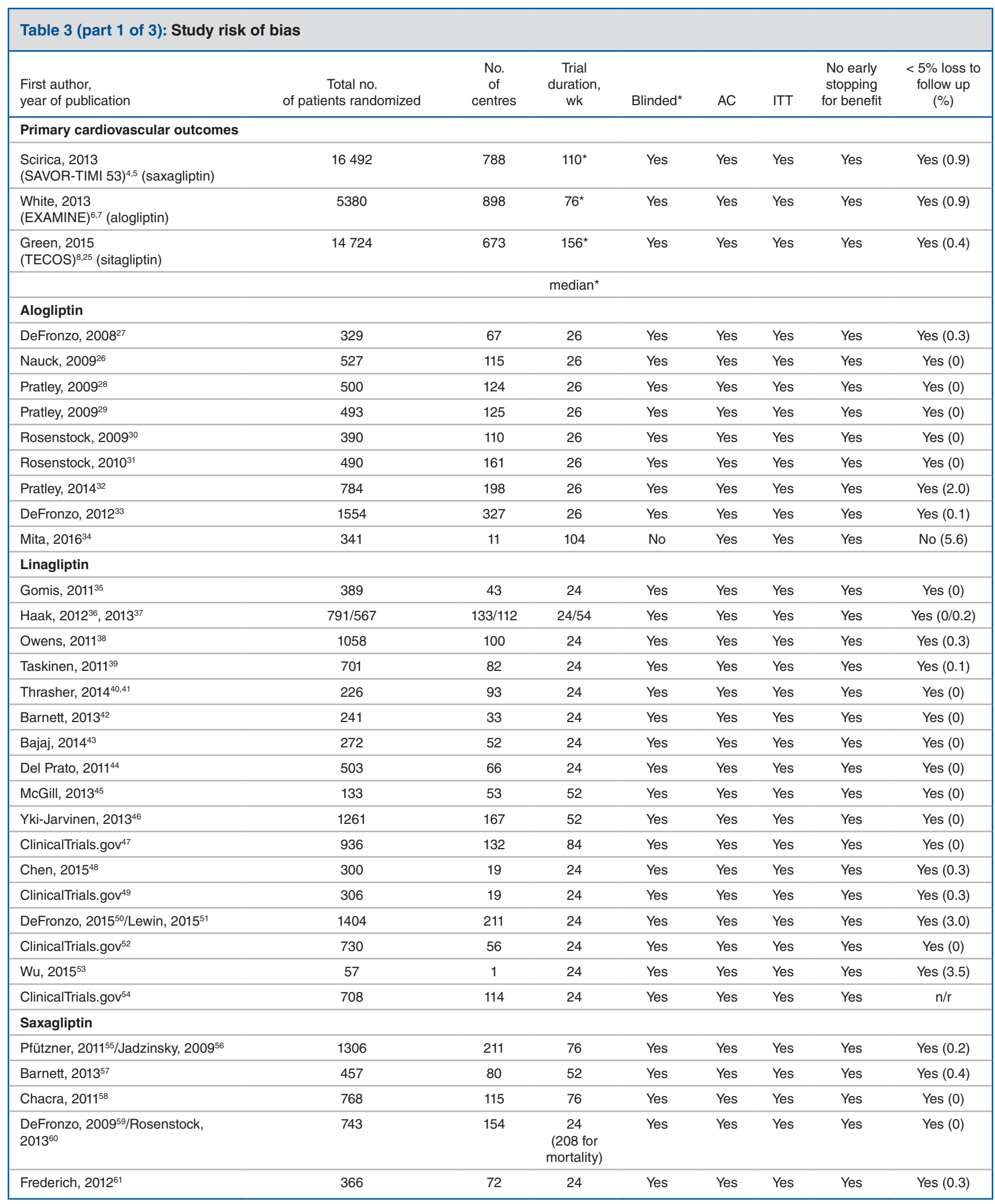




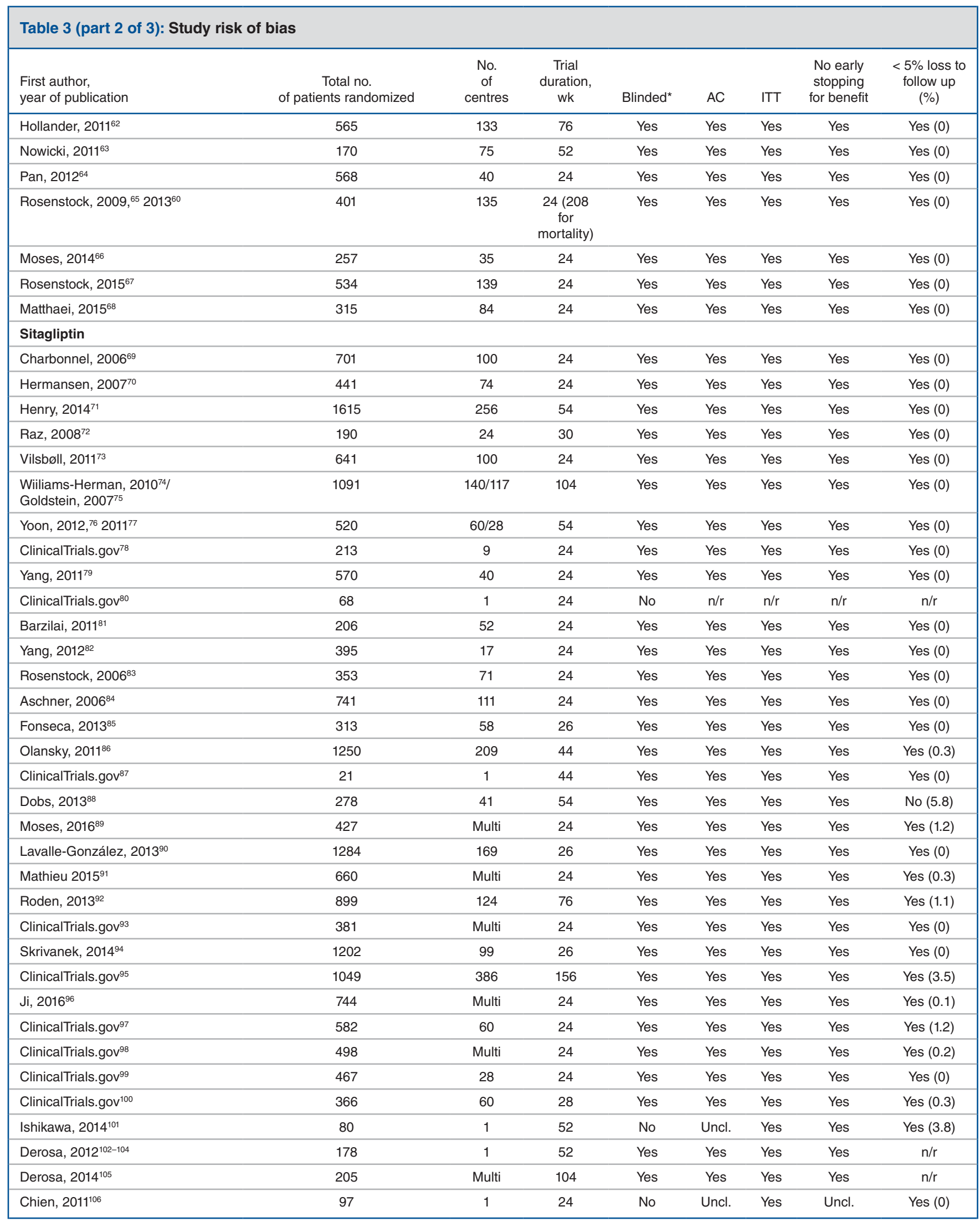




\begin{tabular}{|c|c|c|c|c|c|c|c|c|}
\hline $\begin{array}{l}\text { First author, } \\
\text { year of publication }\end{array}$ & $\begin{array}{l}\text { Total no. } \\
\text { of patients randomized }\end{array}$ & $\begin{array}{c}\text { No. } \\
\text { of } \\
\text { centres }\end{array}$ & $\begin{array}{c}\text { Trial } \\
\text { duration, } \\
\text { wk }\end{array}$ & Blinded* & $A C$ & ITT & $\begin{array}{l}\text { No early } \\
\text { stopping } \\
\text { for benefit }\end{array}$ & $\begin{array}{c}<5 \% \text { loss to } \\
\text { follow up } \\
(\%)\end{array}$ \\
\hline Weinstock, $2015^{107}$ & 1098 & 111 & 26 & Yes & Yes & Yes & Yes & Yes (0) \\
\hline Mita, 2016 108 & 282 & 12 & 104 & No & Yes & Yes & Yes & Yes (2.8) \\
\hline Bosi, $2007^{110}$ & 544 & 106 & 24 & Yes & Yes & Yes & Yes & Yes (0.6) \\
\hline Bosi, 2009111 & 1179 & $>250$ & 24 & Yes & Yes & Yes & Yes & Yes (0.8) \\
\hline Fonseca, $2007^{112}$ & 296 & 68 & 24 & Yes & Yes & Yes & Yes & Yes (0) \\
\hline VIVIDD, $2014^{113}$ & 254 & 94 & 52 & Yes & Yes & Yes & Yes & Yes (0.4) \\
\hline Garber, $2007^{118}$ & 463 & 123 & 24 & Yes & Yes & Yes & Yes & Yes (0) \\
\hline Garber, $2008^{119}$ & 515 & 114 & 24 & Yes & Yes & Yes & Yes & Yes (0) \\
\hline Yang, 2015 & 279 & 18 & 24 & Yes & Yes & Yes & Yes & Yes (0) \\
\hline Foley, 201121/Bunck, $2012^{122}$ & 59 & 1 & 52 & Yes & Yes & Yes & Yes & Yes (0) \\
\hline Pan, $2012^{123}$ & 438 & 17 & 24 & Yes & Yes & Yes & Yes & Yes (0) \\
\hline Lukashevich, $2014^{124}$ & 318 & 55 & 24 & Yes & Yes & Yes & Yes & Yes (0.3) \\
\hline Macauley, $2015^{125}$ & 44 & 1 & 26 & Yes & Yes & Yes & Yes & No (11.4) \\
\hline Ahren, 2004, ${ }^{126} 2005^{127}$ & 107 & 4 & 52 & Yes & Yes & Yes & Yes & Yes (0) \\
\hline Goodman, 2009 & 370 & 67 & 24 & Yes & Yes & Yes & Yes & Yes (0) \\
\hline ClinicalTrials.gov ${ }^{135}$ & 448 & 45 & 24 & Yes & Yes & Yes & Yes & Yes (0.2) \\
\hline \multicolumn{9}{|l|}{ Anagliptin } \\
\hline Yang, 2015 & 109 & 25 & 24 & Yes & Yes & Yes & Yes & Yes (0.9) \\
\hline
\end{tabular}


Table 4 (part 1 of 2): Comparison of current meta-analysis and previously published meta-analyses

\begin{tabular}{|c|c|c|c|c|c|c|c|}
\hline $\begin{array}{l}\text { Meta- } \\
\text { analyses, first } \\
\text { author, year }\end{array}$ & $\begin{array}{l}\text { Analysis } \\
\text { included only } \\
\text { RCTs in which } \\
\text { randomized } \\
\text { groups differ by } \\
\text { DPP-4 inhibitor } \\
\text { treatment to } \\
\text { avoid the } \\
\text { confounding } \\
\text { effect of other } \\
\text { medications }\end{array}$ & $\begin{array}{l}\text { Statistically } \\
\text { compared } \\
\text { HF } \\
\text { outcomes } \\
\text { between } \\
\text { different } \\
\text { DPP-4 } \\
\text { inhibitors }\end{array}$ & $\begin{array}{c}\text { Additional } \geq \\
\text { 24-week } \\
\text { follow-up DPP-4 } \\
\text { inhibitor v. } \\
\text { placebo RCTs/ } \\
\text { enrolled } \\
\text { patients with } \\
\text { HF events } \\
\text { included in the } \\
\text { current } \\
\text { meta-analysis }\end{array}$ & $\begin{array}{l}\text { Avoidance of } \\
\text { inadvertent double } \\
\text { counting of some } \\
\text { included RCTs }\end{array}$ & $\begin{array}{l}\text { Inclusion } \\
\text { of all }{ }^{*} \mathrm{HF} \\
\text { outcomes } \\
\text { for } \\
\text { EXAMINE } \\
\text { Trial }^{7}\end{array}$ & $\begin{array}{l}\text { Inclusion of } \\
\text { most } \\
\text { recently } \\
\text { published } \\
\text { HF results } \\
\text { for VIVIDD } \\
\text { Trial113 }\end{array}$ & Main conclusions \\
\hline \multicolumn{8}{|c|}{ Including TECOS } \\
\hline $\begin{array}{l}\text { Current } \\
\text { meta-analysis }\end{array}$ & Yes & Yes & (reference) & Yes & Yes & Yes & $\begin{array}{l}\bullet 13 \% \text { increase in HF risk } \\
\text { only statistically significant } \\
(p=0.03 \text { ) if results of } \\
\text { smaller RCTs added to } \\
\text { large cardiovascular safety } \\
\text { RCTs } \\
\text {-differences between } \\
\text { agents not statistically } \\
\text { significant (interaction } p= \\
0.07-0.12 \text { ) }\end{array}$ \\
\hline $\mathrm{Li}, 2016^{151}$ & No & No & $\begin{array}{l}10 \mathrm{RCTs} / \\
5541 \text { patients }\end{array}$ & Yes & No & Yes & $\begin{array}{l}-12 \% \text { increase in HF risks } \\
(p=0.05) \text { pooling HF } \\
\text { hospitalization outcomes } \\
\text { from } 5 \text { RCTs only; no } \\
\text { significant increase in HF } \\
\text { for the remaining RCTs v. } \\
\text { all comparators }\end{array}$ \\
\hline Abbas, $2016^{149}$ & Yest & No & $\begin{array}{l}29 \mathrm{RCTs} / \\
18097 \\
\text { patients† }\end{array}$ & Yes & No & $-\ddagger$ & $\begin{array}{l}\text {-non-significant } 11 \% \\
\text { increase in HF risk }(p= \\
0.19) \text { pooling only the } 3 \\
\text { large cardiovascular safety } \\
\text { RCTs but not including all } \\
\text { HF outcomes for } \\
\text { EXAMINE }\end{array}$ \\
\hline $\begin{array}{l}\text { Kongwat- } \\
\text { charapong, } \\
2016^{150}\end{array}$ & No & No & $\begin{array}{l}\text { 4 RCTs/ } \\
1639 \text { patients }\end{array}$ & Yes & Yes & No & $\begin{array}{l}\text {-non-significant } 11 \% \\
\text { increase in HF risk ( } p= \\
0.06 \text { ) v. all comparators } \\
\text {-highlighted increase in HF } \\
\text { for saxagliptin but } \\
\text { differences not statistically } \\
\text { compared with other } \\
\text { agents }\end{array}$ \\
\hline
\end{tabular}


Table 4 (part 2 of 2): Comparison of current meta-analysis and previously published meta-analyses

\begin{tabular}{|c|c|c|c|c|c|c|c|}
\hline $\begin{array}{l}\text { Meta- } \\
\text { analyses, first } \\
\text { author, year }\end{array}$ & $\begin{array}{l}\text { Analysis } \\
\text { included only } \\
\text { RCTs in which } \\
\text { randomized } \\
\text { groups differ by } \\
\text { DPP-4 inhibitor } \\
\text { treatment to } \\
\text { avoid the } \\
\text { confounding } \\
\text { effect of other } \\
\text { medications }\end{array}$ & $\begin{array}{l}\text { Statistically } \\
\text { compared } \\
\text { HF } \\
\text { outcomes } \\
\text { between } \\
\text { different } \\
\text { DPP-4 } \\
\text { inhibitors }\end{array}$ & $\begin{array}{c}\text { Additional } \geq \\
24 \text {-week } \\
\text { follow-up DPP-4 } \\
\text { inhibitor v. } \\
\text { placebo RCTs/ } \\
\text { enrolled } \\
\text { patients with } \\
\text { HF events } \\
\text { included in the } \\
\text { current } \\
\text { meta-analysis }\end{array}$ & $\begin{array}{l}\text { Avoidance of } \\
\text { inadvertent double } \\
\text { counting of some } \\
\text { included RCTs }\end{array}$ & $\begin{array}{c}\text { Inclusion } \\
\text { of all* HF } \\
\text { outcomes } \\
\text { for } \\
\text { EXAMINE } \\
\text { Trial }^{7}\end{array}$ & $\begin{array}{l}\text { Inclusion of } \\
\text { most } \\
\text { recently } \\
\text { published } \\
\text { HF results } \\
\text { for VIVIDD } \\
\text { Trial }{ }^{113}\end{array}$ & Main conclusions \\
\hline \multicolumn{8}{|l|}{ Pre-TECOS } \\
\hline $\begin{array}{l}\text { Monami, } \\
2014^{152}\end{array}$ & No & No & $\begin{array}{l}8 \text { RCTs/ } \\
17463 \text { patients }\end{array}$ & $\begin{array}{l}\text { No } \\
\text { (double counted } \\
\text { NCT01028391 } \\
\text { which was an extension } \\
\text { of NCT0039763177) }\end{array}$ & No & $-\ddagger$ & $\begin{array}{l}\cdot 19 \% \text { increase in HF odds } \\
(p=0.015) \text { v. all } \\
\text { comparators } \\
\text { •highlighted increase in HF } \\
\text { for saxagliptin but } \\
\text { differences not statistically } \\
\text { compared with other } \\
\text { agents }\end{array}$ \\
\hline Wu, $2014^{154}$ & No§ & No & $\begin{array}{l}15 \mathrm{RCTs} / \\
19339 \\
\text { patients }\end{array}$ & $\begin{array}{l}\text { No } \\
\text { (double counted } \\
2 \text { publications } \\
\text { for NCT00327015 } 55,56 \text { ) }\end{array}$ & No & No & $\begin{array}{l}\cdot 16 \% \text { increase in HF risk ( } p \\
=0.04) \text { v. all comparators } \\
\text { and } 17 \% \text { increase }(p= \\
0.03) \text { v. only placebo } \\
\text { comparators }\end{array}$ \\
\hline $\begin{array}{l}\text { Savarse, } \\
2015^{153}\end{array}$ & No & No & $\begin{array}{l}9 \text { RCTs/ } \\
18055 \text { patients }\end{array}$ & $\begin{array}{l}\text { No } \\
\text { (double counted } \\
\text { NCT00915772 } \\
\text { which was an extension } \\
\text { of NCT0079816136) }\end{array}$ & No & No & $\begin{array}{l}-16 \% \text { increase in HF risk ( } p \\
=0.03 \text { ) v. all comparators } \\
\text { pooling long-term follow up } \\
\text { RCTs but no increase } \\
\text { pooling short-term follow } \\
\text { up RCTs }\end{array}$ \\
\hline \multicolumn{8}{|c|}{ 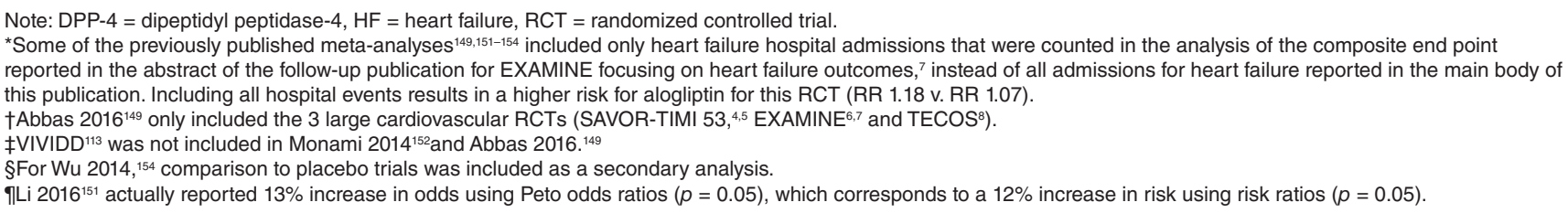 } \\
\hline
\end{tabular}




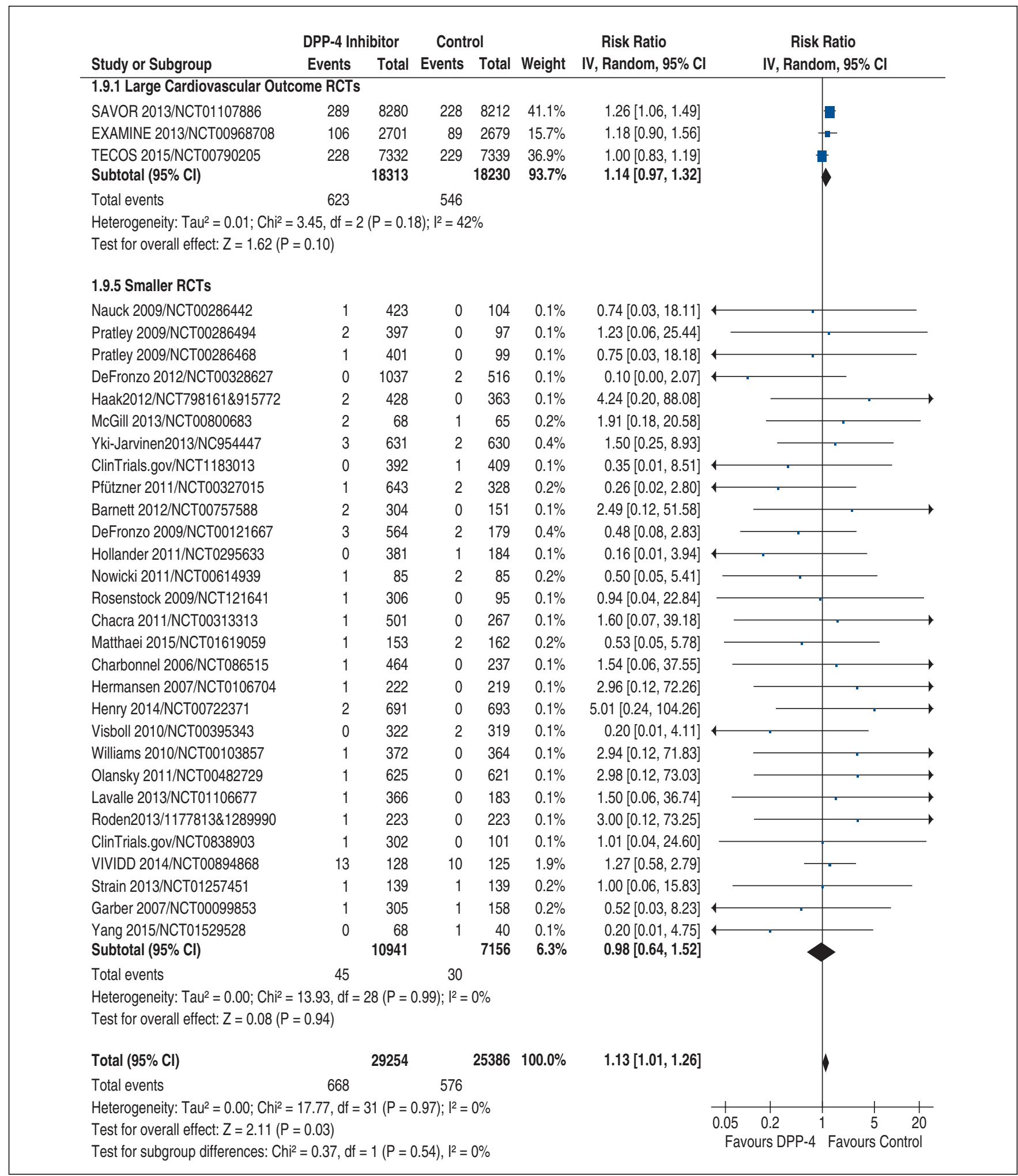

Figure 2: Forest plot for heart failure, large versus small trials. Individual and pooled risk ratios (RRs) with 95\% confidence intervals (Cls) for randomized controlled trials (RCTs) with a primary outcome that included cardiovascular outcomes and reported the number of patients in each treatment group that were admitted to hospital for heart failure as an adjudicated primary or secondary outcome, as well as smaller RCTs reporting at least 1 patient with heart failure for which outcomes were not necessarily adjudicated and patients not necessarily admitted to hospital. The pooled RRs with $95 \% \mathrm{Cls}$ were calculated using random-effects models. Weight refers to the contribution of each study to the overall pooled estimate of treatment effect. Each square and horizontal line denotes the point estimate and $95 \% \mathrm{Cl}$ for each trial's RR. The diamonds signify the pooled RR; the diamond's centre denotes the point estimate and width denotes the $95 \% \mathrm{Cl}$. 


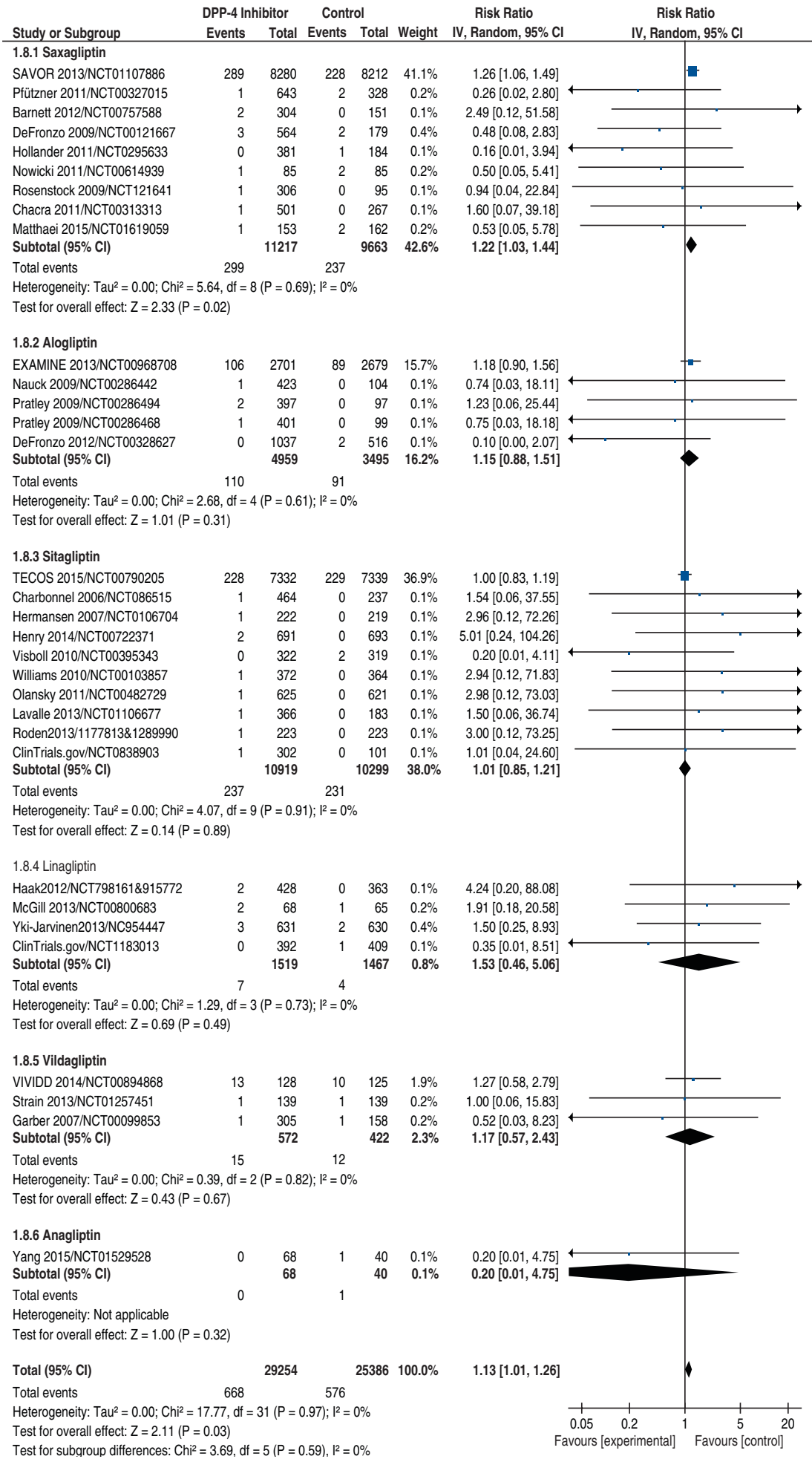

Figure 3: Forest plot for heart failure by DPP-4 inhibitor. Individual and pooled risk ratios (RRs) with 95\% confidence intervals (Cls) for larger and smaller randomized controlled trials (RCTs) by DPP-4 inhibitor. Interaction $p$ values comparing RRs between pairs of subgroups of RCTs using different DPP-4 inhibitors were all nonsignificant. For the most extreme difference between saxagliptin RCTs and sitagliptin RCTs, interaction $p=0.13$ (interaction $p=0.07$ comparing RR for only SAVOR-TIMI $53 \mathrm{v}$. TECOS). The pooled RRs with $95 \% \mathrm{Cl}$ were calculated using random-effects models. Interaction $p$ values were calculated using $Z$ tests. Weight refers to the contribution of each study to the overall pooled estimate of treatment effect. Each square and horizontal line denotes the point estimate and $95 \% \mathrm{Cl}$ for each trial's RR. The diamonds signify the pooled RR; the diamond's centre denotes the point estimate and width denotes the $95 \% \mathrm{Cl}$. 


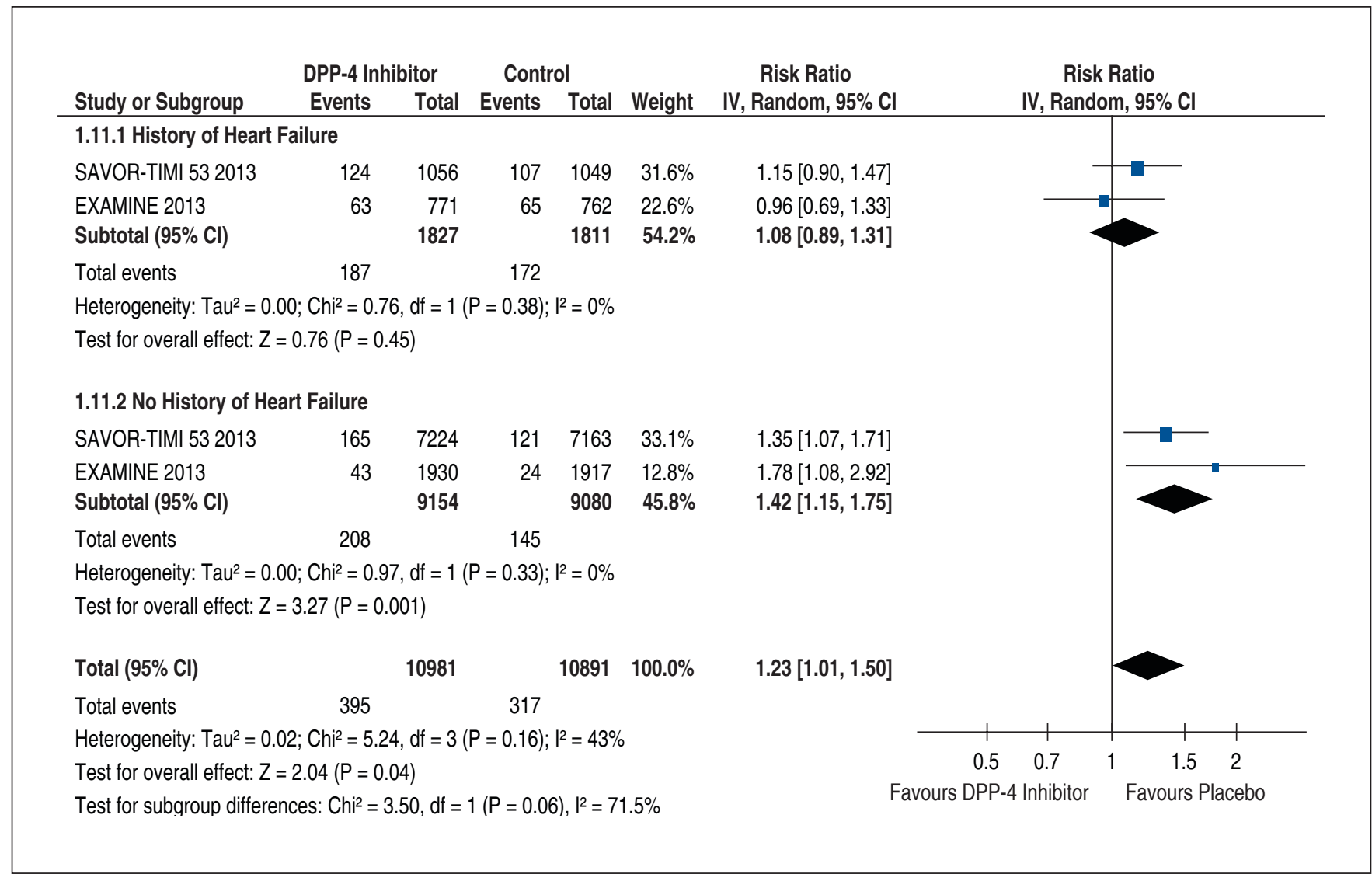

Figure 4: Forest plot for heart failure requiring hospital admission by previous history of heart failure. Individual and pooled risk ratios (RRs) with $95 \%$ confidence intervals (Cls) for the outcome of heart failure requiring hospital admission in subgroups of patients with versus without previous heart failure in SAVOR-TIMI 53 and EXAMINE, the only RCTs that provided these data. Average rates of heart failure requiring hospital admission were $9.9 \%([124+107+63+65] /[1056+1049+771+762]=359 / 3638)$ in patients with versus $1.9 \%([165+121+43+24] /[7224+$ $7163+1930+1917]=353 / 18234)$ in patients without a prior history of heart failure. In this analysis, the heterogeneity in the overall analysis $\left(I^{2}\right.$ $=43 \%)$ is reduced $\left(I^{2}=0 \%\right)$ within each subgroup. The pooled RRs with $95 \%$ Cls were calculated using random-effects models. Interaction $p$ values were calculated using $Z$ tests. Weight refers to the contribution of each study to the overall pooled estimate of treatment effect. Each square and horizontal line denotes the point estimate and $95 \% \mathrm{Cl}$ for each trial's RR. The diamonds signify the pooled RR; the diamond's centre denotes the point estimate and width denotes the $95 \% \mathrm{Cl}$. 